\title{
Identificação Pessoal
}

\author{
(Apontamentos)
}

(Continuação IV)

\section{Carlos Cunha}

(Do Serviço de Identificação da Aeronáutica)

\section{MÉtodo Juan Vucetich. Tipos fundamentais, ClassificaÇão}

\section{- E SUBCLASSIFICAÇÃo}

$\mathrm{E}$

STE Sistema poderia ser narrado resumidamente, conforme sugerem os livros que tratain da Datiloscopia.

As Instruçốes, de que trata a Portaria n. ${ }^{\circ} 415$, de 19 de outubro de 1953, do $\mathrm{Ex}^{\text {mo }}$. Senhor Diretor-Geral do D.A.S.P., pedem, em seu item 15, o que acima foi transcrito.

Os técnicos em Datiloscopia têm falado sôbre o sistema que será tratado nêste "ponto" (item), mas, no tocante aos quatro tipos fundamentais, do modo da classificação dos mesmos e do arquivamento das individuais dactiloscopicas, sem, no entanto, esclarecerem os pormenores importantes do processo lançado em 1891, pelo técnico policial austríaco.

Aqui, em face do rigor observado nos últimos concursos promovidos pelo D.A.S.P., transcrições serão feitas dos originais trabalhos de VucETich; outras do mesmo autor, serão conhecidas por intermédio de autores outros, a fim de que o aluno ou candidato fique ou possa ficar mais ou menos informado sôbre o Sistema Dactiloscópico Argentino.

O sistema de Icnofalangometria (hoje Datiloscópico Argentino)teve, inicialmente, duas fases: uma, de 40 tipos nucleares, cujas individuais, classificadas de acôrdo com a nomeclatura galtoniana, eram arquivadas num armário de 150 "casillas"; outra, de 101 tipos, em que elas eram arrumadas, segundo a marcação proposta por VUCETICH, num armário de 230 "casillas".

Em 1896 (dezembro), quando êsse processo passou a chamar-se "Sistema Datiloscópio Argentino", entrou na terceira e última fase, reduzidos, já, a 4, os 101 tipos da $2 .^{\text {a }}$ fase experimental-classificativa dos dactilogramas.

Método Juan Vucetich (Origem) - Os estudos de VucETich, a respeito da identificação do homem pelo processo dactiloscópico, datam de julho de 1891. 
O técnico austríaco (naturalizado cidadão argentino) para lançar, em primeiro de setembro de 1891 , o sistema que denominou de "icnofalangometria", baseou-se no célebre artigo de HENRY DE VARIGNY, intitulado "Les empreintes digitales d'aprés Galton", publicado em "Revue Scientifique", de París, tomo 47, n. 18, de 2 de maio do ano acima citado, em que o jornalista francês se referia às investigações de PURKINJE (de 1823) e à conferência levada a efeito por GaLton, perante a Royal Society, de Londres, em 27 de novembro de 1890 e reproduzida em "Philossophical Transactions", em 3 de abril (Vucetich diz março) do ano seguinte, sob o título "The Patterns in Thumb and Finger Marks".

A Revista de que se serviu VARIGNY, para citar, em resumo, os estudos de Purkinje, Herschel, Galton, Feré, Testut, Forgeot e outros foi, pelo engenheiro Francisco SEguI, por esquecimento, deixada à mesa

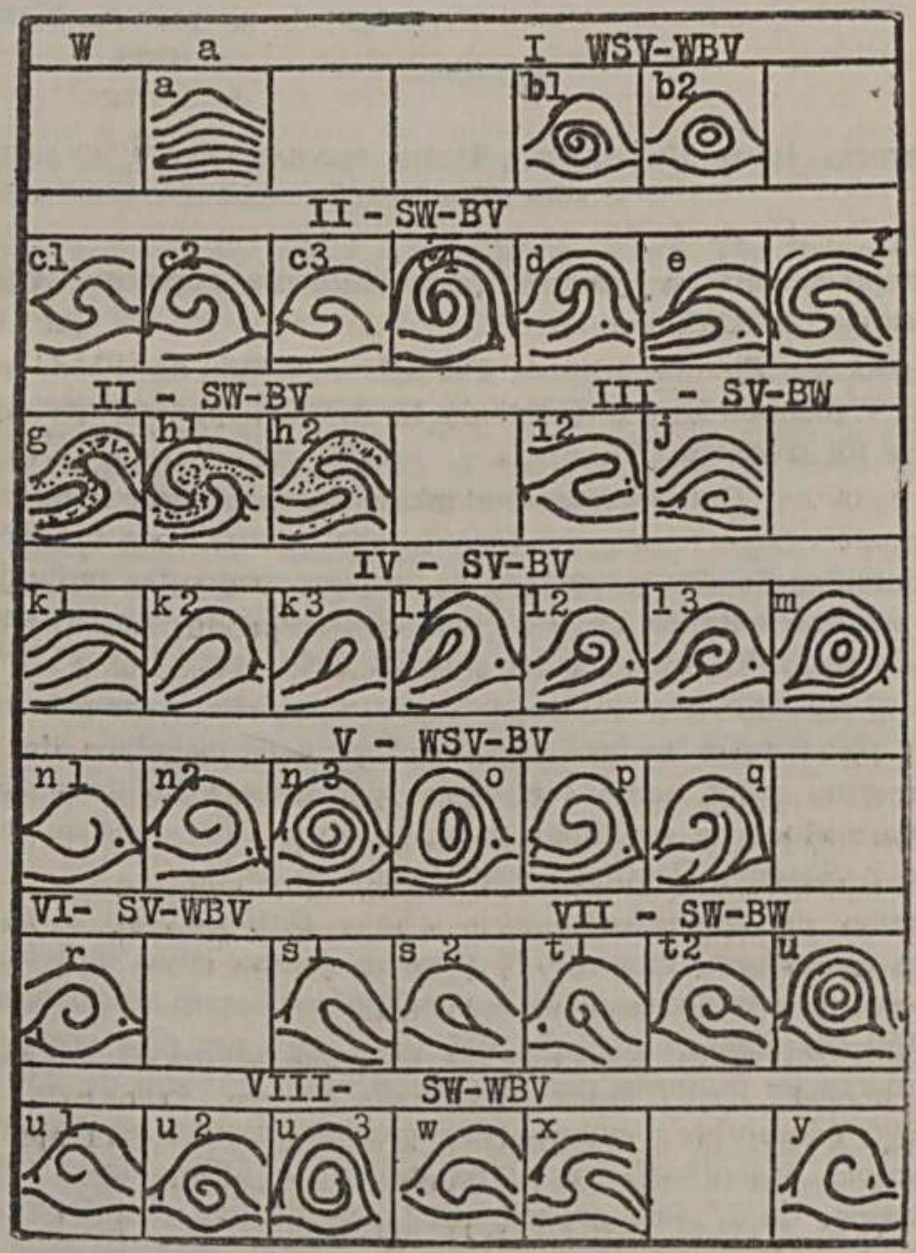

Fig. 46 - Quadro das dez classes e quarenta tipos nucleares de Galton, segundo Valenzuela 
do Capitão de Fragata D. Guilherme J. Nunes que, na época, exercia o cargo de Chefe de Polícia da Provincia de Buenos Aires.

D. Guilhermo J. Nunes, de posse da aludida Revista, chamou a VuCETICH, já incumbido de organizar o Serviço de Identificação e nêle introduzir, a antropometria, para anexá-1o à "Oficina de Estatística", e disse: "Quem sabe se você, com as indicaçōes que contém, não chegará a completar, com êsse processo, o sistema antropométrico e talvez instituir um sistema por meio das impressões digitais".

O resumo de VARIGNY reproduziu os 38 tipos nucleares de Galton (alguns autores mencionam 40 fig. 46 . No quadro reproduzido por VuCETICH, em "Dactiloscopia Comparada", lê-se 38 (trinta e oito) vêzes o nome de Galton, conforme se vê a fig. 7, que levados foram, por Vucetich, para 101 , em 1893, para arquivá-los, em seguida, num armário de 230 "casillas".

Vucetich, de posse dos estudos de Galton (isso, em julho) procurou logo interessar-se pela classificação dos dactilogramas e do modo de como obtê-los, e em setembro, iniciou a identificação de 23 criminosos.

Em dezembro do mesmo ano, a Côrte de Justiça de Buenos Aires, reconhecendo o valor do novo Sistema, permitiu que se identificasse 645 presos do cárcere de La Plata, dentre os quais 7 registavam antecedentes.

Em 1892 (dezembro) Vucetich, por meio das impressōes digitais sangrentas provou a culpabilidade da mulher FrancISCA RoJAS, que vinha comprometendo um seu vizinho, pelo assassinato de seus dois filhos.

Em 1896, quando lançou a 2. ${ }^{\text {a }}$ edição de Instrucciones Generales para el Sistema de Filiación - "Provincia de Buenos Aires", tudo procurou esclarecer sôbre o mérito das impressões digitais no campo da identificação humana.

Nêsse trabalho tratou da perenidade, individualidade e variabilidade das aludidas impressões e do modo pelo qual elas são produzidas na face palmar, até às extremidades dos dedos e da disposição de suas linhas na falangeta, em relação ao eixo do dedo.

Denominou de "sistema perpendicular" as linhas que constituem o "Sistema Marginal", de "oblícuo", às do "Sistema Basilar" e de "desenho" ("Patterns" de GaltoN), o "núcleo" do dactilograma.

A respeito dêsses três sistemas de linhas, disse Vucetich: "Se observarmos uno de nuestros dedos, veremos que el sentido general de las líneas es perpendicular al eje en su base, y que estas, partiendo de una cara lateral, van poco más ó menos directamente á la otra".

"En la extremidad de la uña se observa que las líneas san paralelas al eje del dedo y que pasan de una cara lateral á la otra. Entre estas dos clases extremidades, las unas perpendiculares y las otras oblicuas al eje, se encontran los dibujos (o autor refere-se ao "núcleo") de que se trata".

"Em algunos casos no existen estos; pero, en cambio, las líneas perpendiculares se ponen gradualmente oblicuas, dejando de tener con la cara palmar el paralelismo recíproco que presentan sobre las caras laterales. En éste caso, en lugar de formar arcos figuran asas" (Fig. 47, nêstes Apontamentos). 

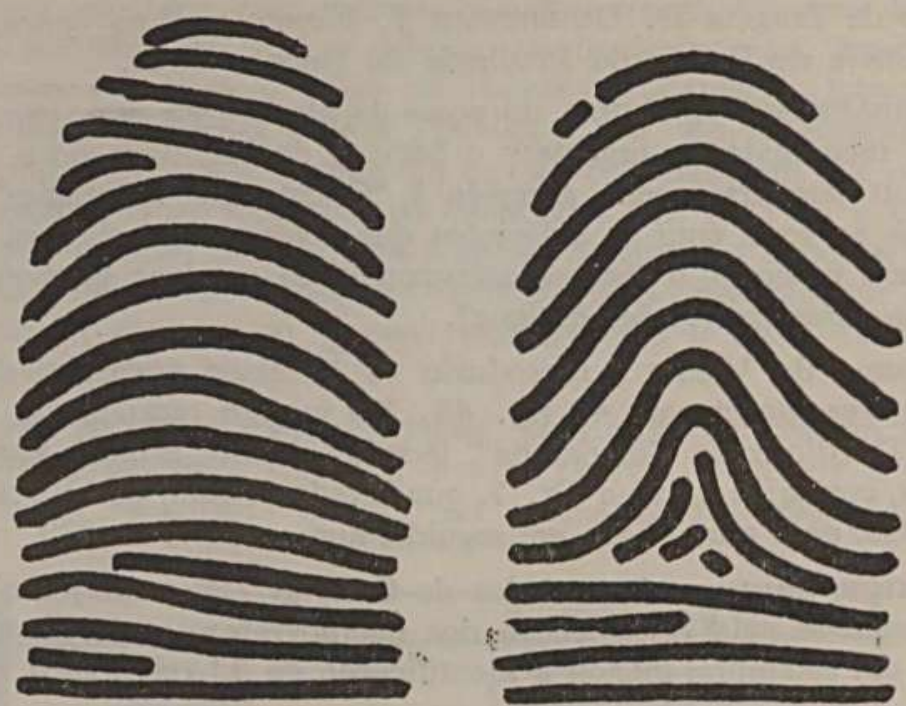

Fig. 47

A respeito dos Núcleos (desenhos), disse: "Generalmente hay entre los dos sistemas, una rede de líneas que forman un dibujo limpio, fácil de distinguir. En otros casos divergen simétricamente en las dos caras laterales del dedo; en otros falta la simetria, y a divergencia no está bien pronunciada sino de un solo lado del dedo, de lo que resulta un espacio palmar irregular $y$ desviado como lo demostran varias figuras esquematicas del cuadro (fig. 48, nêstes Apontamentos).

Análise - Sôbre como analizá-los, á distribuição nas respectivas classes, aconselhou VuCETICH que se seguisse, com uma pena sêca, o curso das "linhas mestras", a partir de $W$ e $V$, que assinalam, respectivamente, os deltas situados entre os sistemas "perpendicular" (marginal) e "oblicuo" (basilar).

Pelo processo sugerido obtem-se SV, SW e WSV, para S, e SV, SW e WBV, para $B$, de que resultam nove combinações citadas, já, por GaLton. Ei-las:

$$
\begin{aligned}
& \text { W S V - W B V } \\
& \text { S W - B V } \\
& \mathrm{S} \text { V }-\mathrm{B} \mathrm{W} \\
& \mathrm{S} \text { V - W B V } \\
& \text { W S V - E V } \\
& \mathrm{S} V-\mathrm{W} B \mathrm{~V} \\
& \text { SW - B W } \\
& \text { W S V - B W } \\
& \text { S W - W B V }
\end{aligned}
$$

por meio dos quais VUCETICH classificava o polegar e anular direitos na ficha dacadactilas, cujo arquivamento fazia num armário de 150 "casillas", criado na primeira fase do sistema de "Icnofalangometria". 
As combinações dadas são fàcilmente encontradas, estudando-se o esquema da fig. 5, em que há uma vertical S-B, cortada por uma horizontal W-V, e os dactilogramas da Fig. 6.

Freqüência đos tipos (no sistema citado). VucEtich chegou à conclusão de que "as classificações mais freqüentes se observam nos desenhos (esquemas) $s 1, s 2, i, r$ e $y$ " (fig. 48).

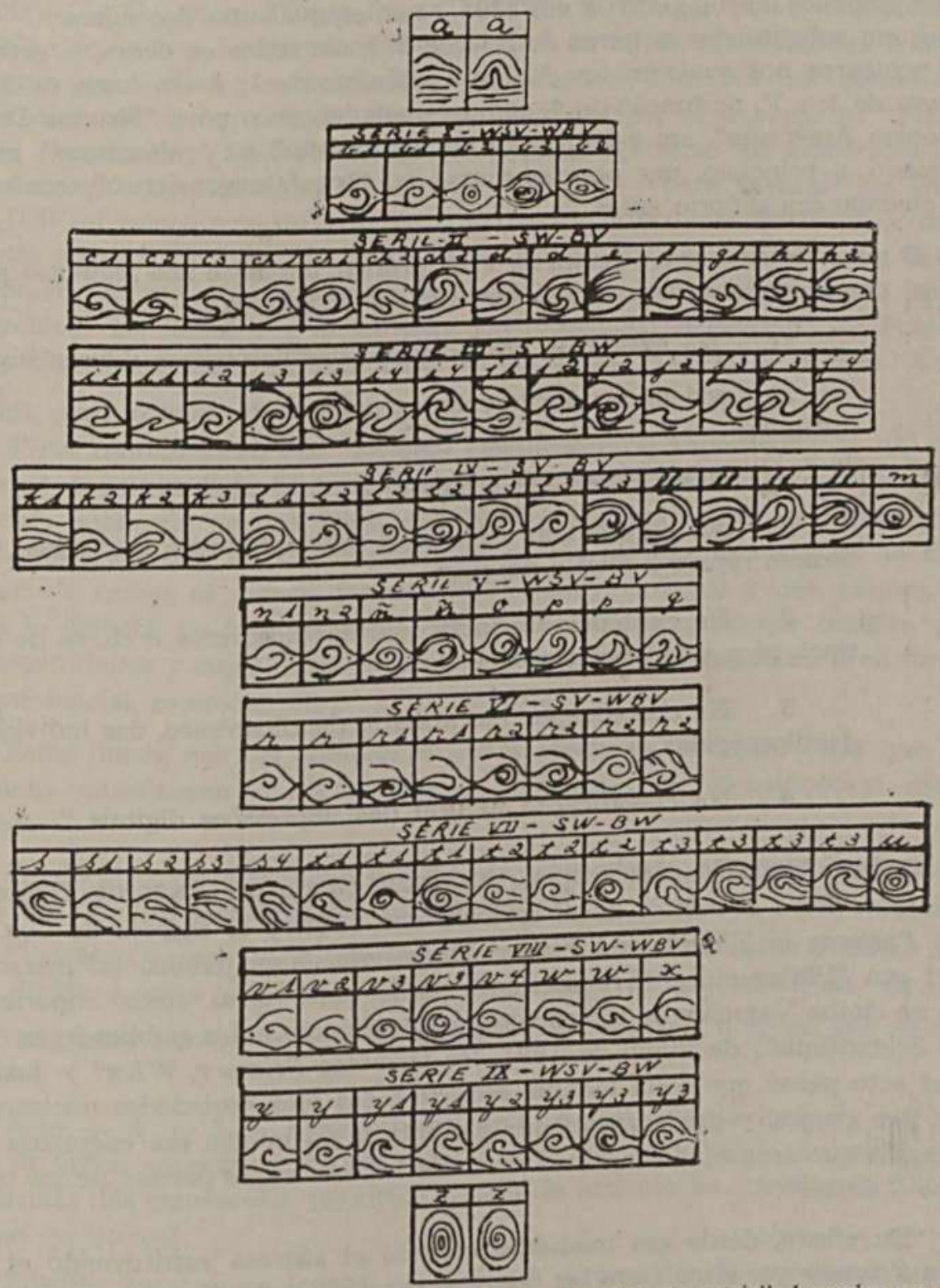

Fig. 48 - Os 101 tipos do sistema de "Icnoialanğomet:ia", lançados em 1893 
Classificação dos tipos de "Icnofalangometria" - De 1891 a 24 de dezembro de 1896 VuCETICH seguiu, à risca, as teorias "galtonianas", isto é, classificava, por meio de letras, os tipos e subtipos do polegar e anular direitos impressos na ficha decadactilar, cuja extensão fazia com os iguais dedos da mão esquerda.

Em 1896, ainda, passou a usar, em substituição das letras (vide combinações dađas em "Análise" e fig. 46, dêste ponto), os números 1, 2, 3 e 4 (êstes símbolos lançou GaLton em 1895, como equivalentes dos sígnos dados em substituição às letras $\mathrm{A}, \mathrm{R}, \mathrm{U}$ e W) em todos os dedos, à exceção dos polegares, nos quais anotou $\mathrm{A}$, como sinônimo de $1 ; \mathrm{I}$, em lugar de $2 ; E$, em vez de 3 ; e $V$, na função de 4 , com os quais lançou o novo "Sistema Dactiloscópico Argentino", em substituição ao "galtoniano" ou "galtonismo", assim chamado, a princípio, por pessoas outras ou "Icnofalangométrico", conforme the chamou seu próprio autor.

O novo Sistema, sob o ponto de vista prático, baseia-se nos seguintes princípios, obedecida a ordem citada por SISLÁN RodRíguez:

“1. Na existência dos desenhos dactiloscópicos diferenciáveis:

a) podem ser fàcilmente agrupados em quatro tipos fundamentais;

b) classificáveis em arquivos; e

c) que apresentam variedades suficientemente numerosas, que tornam rápida e fácil a pesquisa.

2. Na existência da individual dactiloscópica e chave de subtipos para subclassificação.

3. Na classificação, em armário dactiloscópico, das individuais dactiloscópidas.

4. Na classificação natural das impressões digitais."

Quanto à adoção dêsses tipos, Vucetich, citado por ANTONIo Herrero, declarou: "Pero al recibir en el referido ano (1896) el trabajo de GaLTON The Patterns in Thumb and Finger Marks, etc., que publicó en marzo de 1891 em "Philosophical Transactions", hallé entre otras cosas importantes que no citaba VARIGNY en el artículo que al respecto habia publicado en "Revue Scientifique", de mayo de 1891, los términos Primary, Whorl y Loop y en el acto pensé que seria factible reducir todas esas variedades nucleares a esos tres grupos, y por conseguiente simplificar en mucho esa engorrosa clasificación que aconsejada seguir el curso de las líneas que partian de los triángulos ó deltas".

"En efecto, desde ese momento concebi el sistema sustituyendo el término Primary por Arco (isto fez Galton em 1892), devido a las características de sus lineas, al Whorl lo traduje por Verticilo y al Loop por Presilla, la 
cual, también debido a la característica de la disposición de las líneas, la dividi en Interna y Externa (devido às mesmas "características", GALTON, em 1892, dividiu as Presilhas em $I$ e $O$, sinais êstes substituídos, logo por $U$ e R), resultando por conseguiente cuatro tipos bien caracterizados y inconfundibles".

Os demais trabalhos de GALTON, a respeito da nomenclatura dos tipos de desenhos, foram conhecidos por VuceTich em 1897, conforme êle próprio declarou: "Y aqui debo declarar que se en ese tiempo (1896) hubiese conocido las obras de GaLton, "Finger Prints" (1892) y "Finger Prints Directories" (1895) que no tuvo la deferencia de enviarme en 1897 , talvez hubiera tratado de seguir sus huellas y no hubiera, en consecuencia, descubrir mi sistema que tan distinto es de las combinaciones proyectadas por él, aunque en "Finger Prints Directories" (1895) insinúa que podrían utilizarse los numerales de 1 a 4 como equivalentes de los signos $\cap \backslash / O$ para sustituir las letras $A-R-U \cdot W$ al solo efecto de la maior rapidez en el acto de clasificar, y debo además advertir que Galton jamás se referió despues a esos números ni los usó practicamente, ni jamás pensó tomarlos en cuenta con respecto al orden de archivar las fichas". ("El Sistema Dactiloscópico Argentino" - Polémicas y Cuestiones que ha Suscitado - Antonio Herrero, Buenos Aires, 1926).

Tipos fundamentais (do "Sistema Dactiloscópico Argentino") - "Ã classificaçño dos tipos dêste Sistema observou VucETich, em "Dactiloscopia Comparada", publicada em La Plata, em 1904: "A simple vista todo el mundo puede observar que las líneas papilares de las últimas falanges de la cara palmar de ambas as manos, forman dibujos muy variados y que existen, ya sea á la derecha ya á la izquierda ó en ambos lados, pequenos ángulos, que se llaman deltas y cujas líness se prolongan a derecha ó izquierda ó en forma circunferencial, espiróide, etc.

Estas líneas, que las doninamos lineas diretrices, encerran otras que, en conjunto, constituyen el núcleo que da caracteres de identificación matemática.

Puede observarse también que en otros no existen esos ángulos ó deltas por estar aquellos formados por simples curvas.

Pues bién, la existencia ó inexistencia de los citados ángulos ó deltas permite dividir a tođos los dibujos en cuatro grupos". (Págs. 80-81, ob. cit.).

Os grupos (compreendidos os subtipos), de que fala o autor, são quatro, a saber:

Arco - A ou 1 - Desenho sem delta e sem núcleo, formado por um feixe de linhas aparentemente paralelas, que se vão encurvando, à medida que se afastam das tranversais, paralelas à ruga de articulação. Adelto de Oloriz, e Arco de Locard.

Presilha Interna - I ou 2 - Delta à direita do observador e núcleo formado por uma sucessão de colchetes encaixados uns nos outros, abertos 
e voltados para o lado esquerdo. Dex trodelto de OLORIz e Presilha esquerda de Locard.

Presilha Externa -- E ou 3 - Delta à esquerda do observador e núcleo formado por uma sucessão de alças encaixadas umas às outras, abertas e voltadas para o lado direito. Sinistrodelto de OLORIZ e Presilha direita de LOCARD.

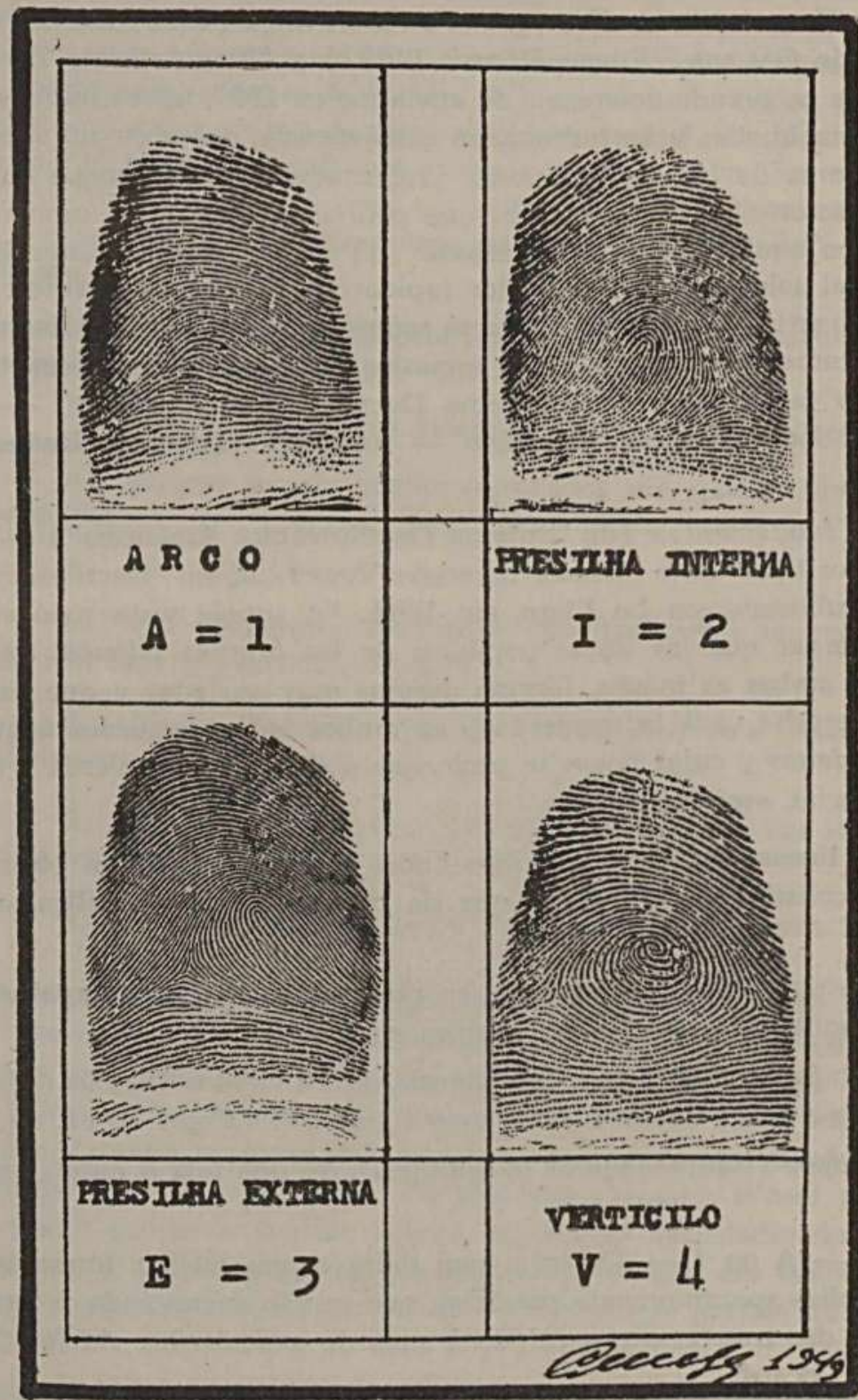

Fig. 49 -- Os quatro tipos fundamentais do Sistema Dactiloscópico Argentino 
VERTICILO - V ou 4 - Dois deltas: um a direita e outro à esquerda do observador e núcleo formario por espiras, círculos, elípses, sinuciosidades, ganchos e formas outras. Bidelto de Oloriz e Verticilo de Locard.

Na mesma obra VuCETICH mencionou três tipos anormais: polidactilia (número de dedos superior ao normal), ectrodactilia (número de dedos inferior ao normal) e sindactilia (dedos ligados entre si). Com 0 (zero), representava os dedos anquilosados e com X, os tipos "anômales", os ilegíveis e os deformados por cicatrizes.

Classificação - Consiste na distinção dos aludidos tipos por meio de símbolos alfabéticos e numéricos. Assim, o Arco, é representado pela letra $A$, se estiver em um ou em ambos os polegares; nos demais dedos, será representado pelo algarismo 1 (um). A Presilha Interna é representada com I (nos polegares) e com 2, nos demais dedos. A Presilha Externa com $E$ (nos polegares) e com 3, nos demais dedos. O Vorticilo se faz representar por $V$ (nos polegares) e com 4, nos demais dedos.

Então:

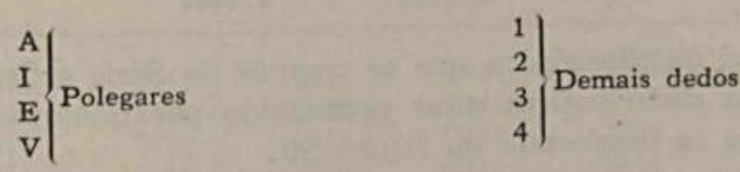

Dessa nomenclatura, resulta a "fórmula dactiloscópica", que é a representação sistemática dos desenhos, por símbolos alfabéticos e numéricos.

Esses símbolos, multiplicados entre si $(4 \times 4 \times 4 \times 4 \times 4 \times 4 \times 4 \times 4 \times 4 \times 4)$ oferecem 1.048.576 fórmulas diferentes, obedecida a seguinte ordem:

\section{MÃO DIREITA}

\section{(Série)}

Polegar

(Fundamental)

A
I
E
V

A

I

V

$$
\begin{array}{cc}
\text { juntado a } \\
", & , \\
, & "
\end{array}
$$

MÃO ESQUERDA

\section{(Seção)}

Polegar

(Subclassificação)

- A

I

E

V
Demais dedos

(Divisão)

256

256

256

$256=1024$ Séries

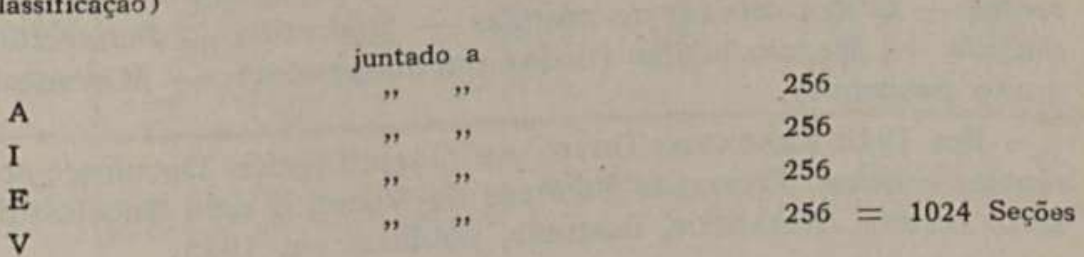


Logo, os dedos da Divisão oferecem 256 combinações, que multiplicadas pelos quatro tipos decorrentes do polegar direito (fundamental) possibilitam 1024 fórmulas para a Série (Mão direita), que são multiplicadas pelo igual número da Seção (Mão esquerda).

Então, 1024 Séries x 1024 Seções $=1.048 .576$ fórmulas dactiloscópicas diferentes, freqüentes umas e raras outras.

Vê-se, de acôrdo com o número possibilitado por essas combinações, que as Séries A-1111 até A-4444 podem-se combinar com as Seções:

$\begin{array}{llll}\text { A-1111 } & \text { I-1111 } & \text { E-1111 } & \text { V-1111 } \\ \text { A-1112 } & \text { I-1112 } & \text { E-1112 } & \text { V-1112, até } \\ \text { A-4444 } & \text { I-4444 } & \text { E-4444 } & \text { V-4444 }\end{array}$

As Seções, também de A-1111 até A-4444, podem-se combinar com as Séries:

$\begin{array}{llll}\text { A-1111 } & \text { I-1111 } & \text { E-1111 } & \text { V-1111 } \\ \text { A-1112 } & \text { I-1112 } & \text { E-1112 } & \text { V-1112, ate } \\ \text { A-4444 } & \text { I-4444 } & \text { E-4444 } & \text { V-4444 }\end{array}$

$\mathrm{Na}$ individual dactiloscópica, que se compõe de Série e Seção, os espaços reservados a cada dedo podem estar preenchido por qualquer dos tipos do Sistema, conforme se depreende da figura 50 .

Subclassificação - Os "princípios em que se baseiam os sistemas de subclassificação", esclarecidos por Sislán RodríGuez, Diretor do Museu Vucetich, de La Plata, são os seguintes: Oloriz.

"1. Na configuração dos desenhos adotados por Vucetich e

2. Na direção e número de linhas: "ridge tracing" e "ridge counting", criados por Galton. Oloriz."

3. Pela dimensão do dactilograma, criado por Heillman e

VuCETiCH, além das variedades dos desenhos mostrados em "Dactiloscopia Comparada" lançou, depois, duas "Chaves" de subclassificação: uma, en que dividiu os "Arcos" em Simples e Anǵtlares; as "Presilhas" (Internas e Externas), em Simples (Altas e Baixas), Ganchosas e Invadidas e os "Verticilos", em Espirais (Simples - Com direção direita - Com direção esquerda), Sinuosos (Com direção direita - Com direção esquerda), Ovoidais (Verticais - Com direção direita - Com direção esquerda, "Anômalos" - Amputados - Anquilosados - Com cicatrizes de panarícios - Com cicatrizes cortantes - Com cicatrizes de pústulas - Sindactilia - Polidactilia - Ectrodactilia - Megalodactilia (dedos muito grandes) - Microdactilia (dedos muito pequenos).

Em 1913 Fernando OrTiz, em "Identificación Dactiloscópica" fez referências a outra "Chave de Subtipos de Vucetich para Subclassificação", que LUiz Reyna Almandos, ilustrada, publicou em 1925. 


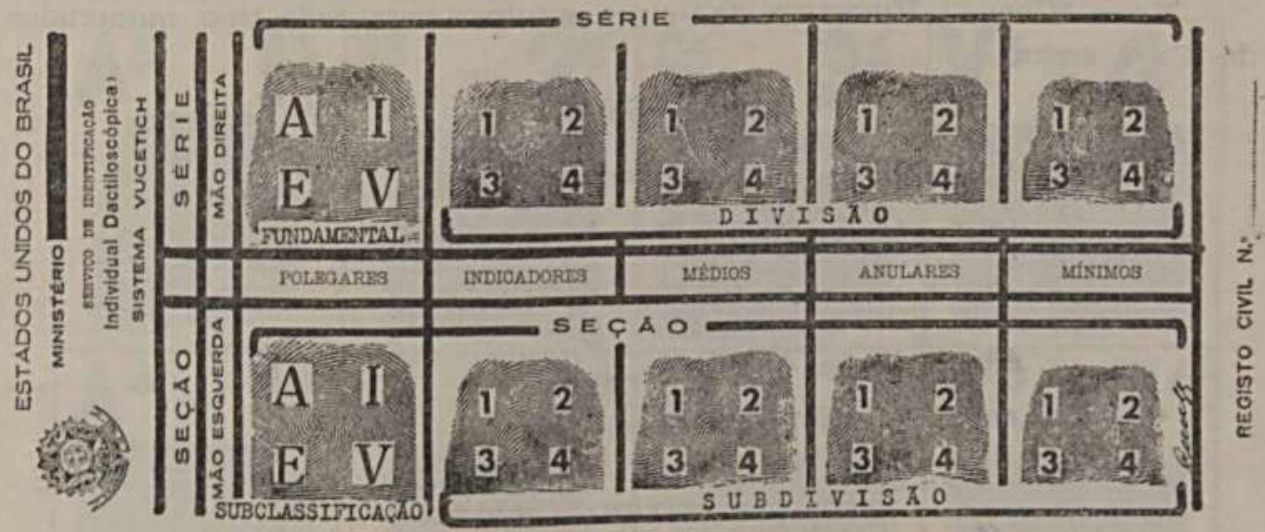

Fig. 50 - Interpretaçāo de uma individual dactiloscópica

\begin{tabular}{|c|c|c|c|c|c|c|c|}
\hline 1111 & 1311 & 2111 & 2311 & 3111 & 3311 & 4111 & 4311 \\
\hline 1112 & 1312 & 2112 & 2312 & 3112 & 3312 & 4112 & 4312 \\
\hline 1113 & 1313 & 2113 & 2313 & 3113 & 3313 & 4113 & 4313 \\
\hline 1114 & 1314 & 2114 & 2314 & 3114 & 3314 & 4114 & 4314 \\
\hline 1121 & 1321 & 2121 & 2321 & 3121 & 3321 & 4121 & 4321 \\
\hline 1122 & 1322 & 2122 & 2322 & 3122 & 3322 & 4122 & 4322 \\
\hline 1123 & 1323 & 2123 & 2323 & 3123 & 3323 & 4223 & 4323 \\
\hline 1124 & 1324 & 2124 & 2324 & 3124 & 3324 & 4124 & 4324 \\
\hline 1131 & 1331 & 2131 & 2331 & 3131 & 3531 & 4131 & 3331 \\
\hline 1132 & 1332 & 2132 & 2332 & 3132 & 3332 & 4132 & 4332 \\
\hline 1133 & 1333 & 2132 & 2333 & 3133 & 3333 & 4133 & 4333 \\
\hline 1134 & 1334 & 2134 & 2334 & 3134 & 3334 & 4134 & 4334 \\
\hline 1141 & 1341 & 2141 & 2341 & 3141 & 3341 & 4141 & 4341 \\
\hline 1142 & 1342 & 2142 & 2342 & 3142 & 3342 & 4142 & 4342 \\
\hline 1143 & 1343 & 2143 & 2343 & 3143 & 3343 & 4143 & 4343 \\
\hline 1144 & 1344 & 2144 & 2344 & 3144 & 3344 & 4144 & 4344 \\
\hline 1211 & 1411 & 2211 & 2411 & 3211 & 3411 & 4211 & 4411 \\
\hline 1212 & 1412 & 2212 & 2412 & 3212 & 3412 & 4212 & 4412 \\
\hline 1213 & 1413 & 2213 & 2413 & 3213 & 3413 & 4213 & 4413 \\
\hline 1214 & 1414 & 2214 & 2414 & 3214 & 3414 & 4214 & 4414 \\
\hline 1221 & 1421 & 2221 & 2421 & 3221 & 3421 & 4221 & 4421 \\
\hline 1222 & 1422 & 2222 & 2422 & 3222 & 3422 & 4222 & 4422 \\
\hline 1223 & 1423 & 2223 & 2423 & 3223 & 3423 & 4223 & 4423 \\
\hline 1224 & 1424 & 2224 & 2424 & 3224 & 3434 & 4224 & 4424 \\
\hline 1231 & 1431 & 2231 & 2431 & 3231 & 3431 & 4231 & 4431 \\
\hline 1232 & 1432 & 2232 & 2432 & 3232 & 3432 & 4322 & 4432 \\
\hline 1233 & 1433 & 2233 & 2433 & 3233 & 3433 & 4233 & 4433 \\
\hline 1234 & 1434 & 2234 & 2434 & 3231 & $343 \pm$ & $423 !$ & 4434 \\
\hline 1241 & 1441 & 2241 & 2441 & 3241 & 3141 & 4241 & 4441 \\
\hline 1242 & $144 ?$ & 2242 & 2442 & $32 \div 2$ & 3442 & 4212 & 4442 \\
\hline 1243 & 1443 & 2243 & 2443 & 3243 & 3143 & 4243 & 4443 \\
\hline 1244 & 1444 & 2244 & 2144 & 3214 & 3144 & 424 & 444 \\
\hline
\end{tabular}

Quadro demonstrativo das 256 combinacĩez que oferecem os dẹoz da Divisc̃o ou da Subdivisão parn a Fundamental ou Subclassificaçäo A - I - E cu V. 
Nessa "Chave", Vucetich deu cinco subtipos para cada tipo, numerados de 5 a 9 , assim:

$$
\text { ARCOS (Subtipos) }
$$

$\mathrm{A}^{5}-1^{5}-$ Arco abobadado

$\mathrm{A}^{6}-1^{6}-$ Com inclinação à esquerda

$\mathrm{A}^{7}-1^{7}-$ Com inclinação à direita

$\mathrm{A}^{8}-1^{8}-$ Angular

$\mathrm{A}^{9}-1^{9}-$ Demais variedades.

PRESILHA INTERNA (Subtipos)

$$
\begin{aligned}
& I^{5}-2^{5}-\text { Normais } \\
& I^{6}-2^{6}-\text { Invadidas } \\
& I^{7}-2^{7}-\text { Interrogantes } \\
& I^{8}-2^{8}-\text { Ganchosas } \\
& I^{9}-2^{9}-\text { Demais variedades } \\
& \quad \text { PRESILHA EXTERNA (Subtipos) } \\
& E^{5}-3^{5}-\text { Normais } \\
& E^{6}-3^{6}-\text { Invadidas } \\
& E^{7}-3^{7}-\text { Interrogantes } \\
& E^{8}-3^{8}-\text { Ganchosas } \\
& E^{9}-3^{9}-\text { Demais variedades. } \\
& V^{5}-4^{5}-\text { Nermicilio (Subtipos) } \\
& V^{6}-4^{6}-\text { Sinuosos } \\
& V^{7}-4^{7}-\text { Ovoidais } \\
& V^{8}-4^{8}-\text { Ganchosos } \\
& V^{9}-4^{9}-\text { Demais variedades. }
\end{aligned}
$$

As presilhas simples, subclassificadas com o expoente 5 , quando repetidas numa individual (Ex: E-3333; I-2222) recebem, como expoente, o número de linhas, que se escreve entre parênteses.

Para isso verifica-se, por meio da "linha de Galton", traçada no disco da "lupa dactiloscópica", o número de linhas situado entre o delta e o "centro nuclear", excluídos da contagem os "pontos" de fixação da referida linha. 
"CHAVE DE SUBTIPOS DE VUCE TICH PARA SUBCLASSIFICAÇÃO"

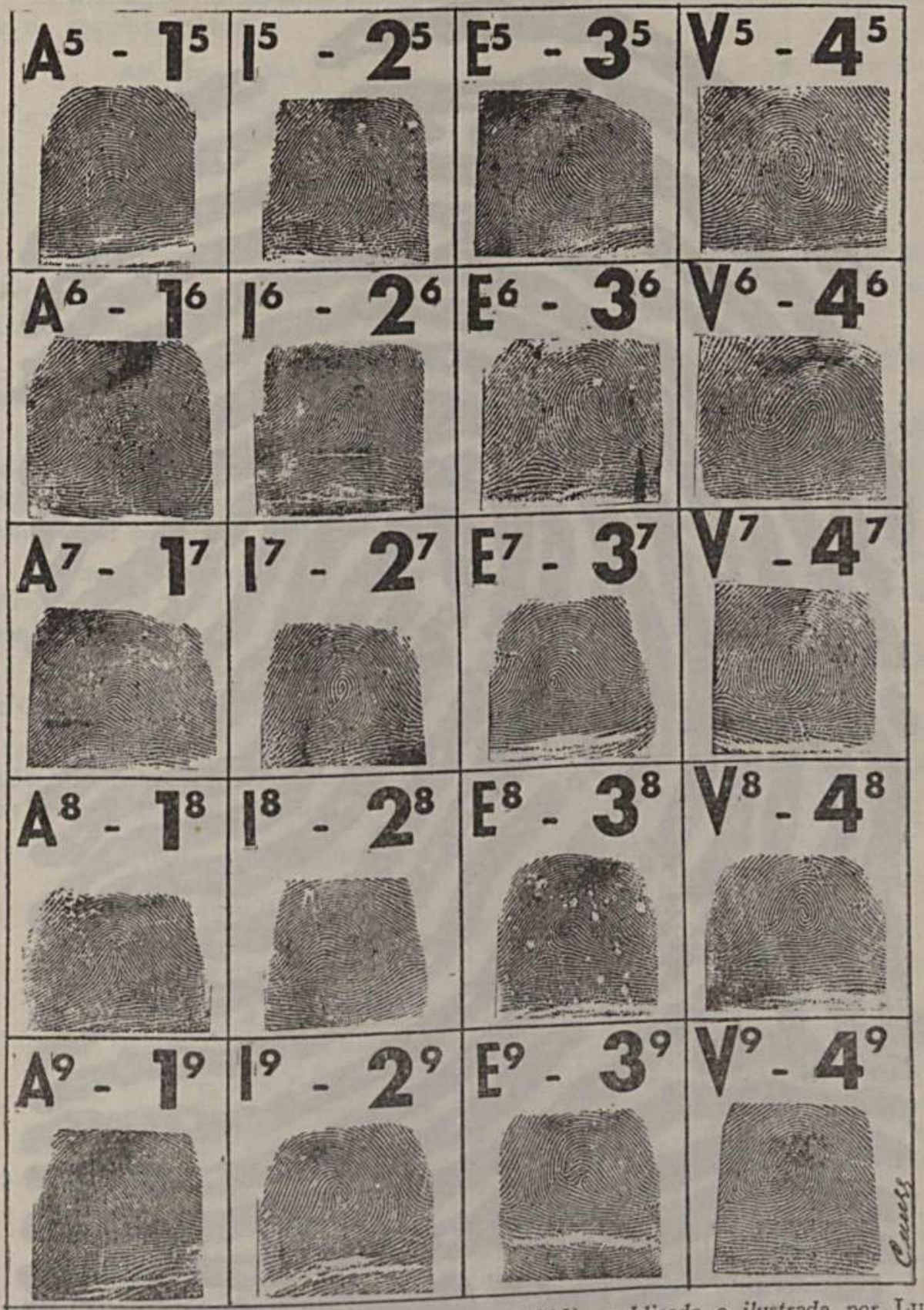

Fig. 51 - Citada por Fernando OrTIz (1916), publicada e ilustrada por LuIs REYN AI.MANDOS, em 1925 


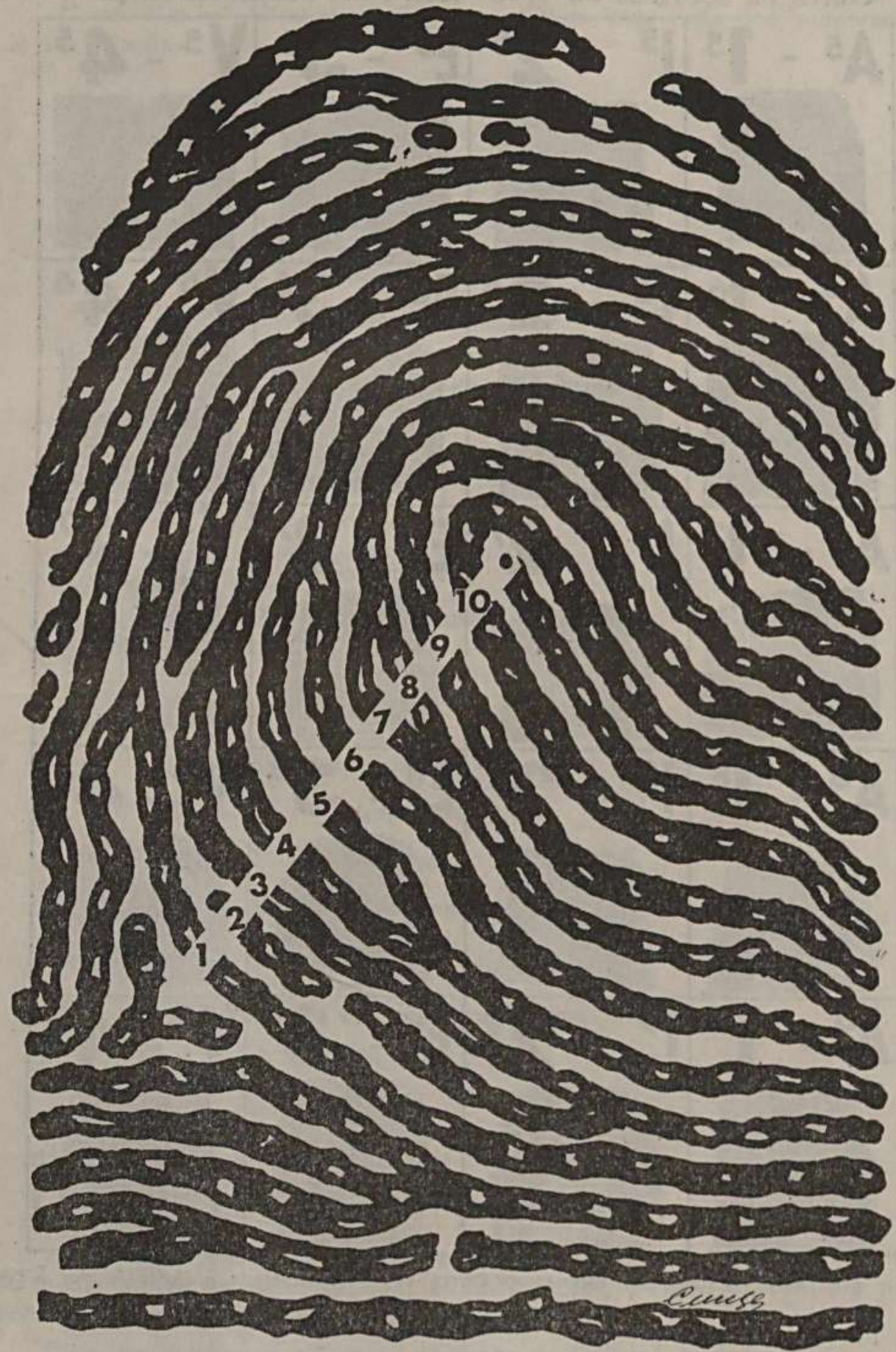

Fig. 52 - Contagem das linhas 
A indicação do número de linhas, segundo a "Chave" de VuCETICH, se faz na seguinte ordem:

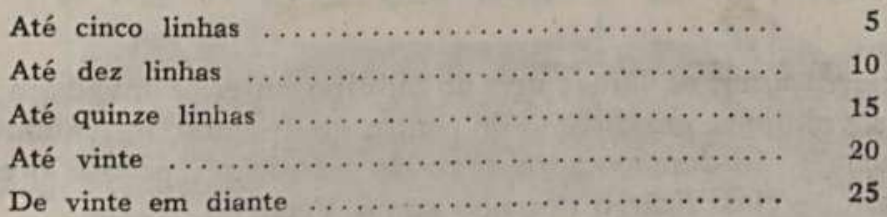

Atualmente, em inúmeras "Chaves" de subclassificação, as presilhas são subdivididas em Pequenas -- P ou Pq., Médias - - Md, e Grandes - Gr ou Gd., ou sòmente em Pequenes - $\mathrm{P}$ ou p, e Grandes - Gr ou gr.

Grafam-se, com maiúsculas, as abreviaturas que se destinarem aos polegares; com minúsculas, se aos outros dedos.

Pela situação dos deltas ("ridge tracing"), os verticilos são subclassificados em convergentes ( $\mathrm{CO}$ ou $\mathrm{co}$ ) e divergentes. Êstes, em delta direito divergente - DDD ou ddd - e delta esquerdo divergente - DED ou ded (vide "ponto" 11, publicado nesta Revista, em número anterior).

Valor dos sistemas desubclassificação - Possibilitar o fracionamento das individuais de "fórmulas numerosas" (fórmulas freqüentes), para facilitar as pesquisas.

Não há uma regra rígida à classificação, isto é, à estruturação das fórmulas das "individuais" da fig. 56 .

A do primeiro plano está classificada e subclassificada segundo a orientação dos técnicos do Instituto Felix Pacheco; a estrutura sugerida por Vucetich se encontra em sua base.

A do segundo plano poderia ser estruturada assim:
F.D.
Polisindactilia
$\mathrm{X}-\mathrm{X} \times \mathrm{X} \mathrm{x}$

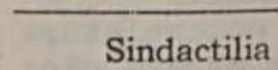
F.D.
F.D. $\frac{X-443 \mathrm{X}}{\mathrm{I}-124 \mathrm{X}}$
ou em F.D. Mãos anômalas.

A fórmula mais correta é aquela que menciona:

$$
\text { F.D. } \frac{\text { Polisindactilia }}{\text { Sindactilia }}
$$

Descrição dos subtipos - As presilhas simples, por VucETrch denominadas normais, não apresentam linhas invasoras, conforme se vê à fig. 51 .

As linhas, partindo de um dos lados do dedo, sobem, contornam um centro real ou imaginário e voltam ao lado de origem, sem se fundirem com as laçadas mais centrais. 
As denominadas invadidas apresentam as laçadas mais internas atingidas pelas hastes superiores das outras alças ou, inda, pela sua própria haste descendente.

Nas interrogantes, as linhas que no subtipo anterior invadiam as imediatas inferiores, voltam-se em direção do centro do desenho, formando um "ponto de interrogação"; são denominados "tipo de transição", porque o seu número de voltas permite classificar o desenho como Verticilo.

Há quem aconselhe classificar em Verticilo os desenhos cujo apresente de 4, inclusive, a mais voltas; autores outros sugerem e classificam, até, aquêles em que há sòmente um círculo ou uma volta espiralada, livre, de angulosidade ou de apêndice.

Verticilo - Pela configuração do núcleo são subclassificados em espirais, ovoidais, sinuosos, ganchosos e demais variedades, isto, no Sistema Vucetich. Autores outros vão mais além. O verticilo ganchoso, na subclassificação dêstes, será tratado nos tipos especiais.
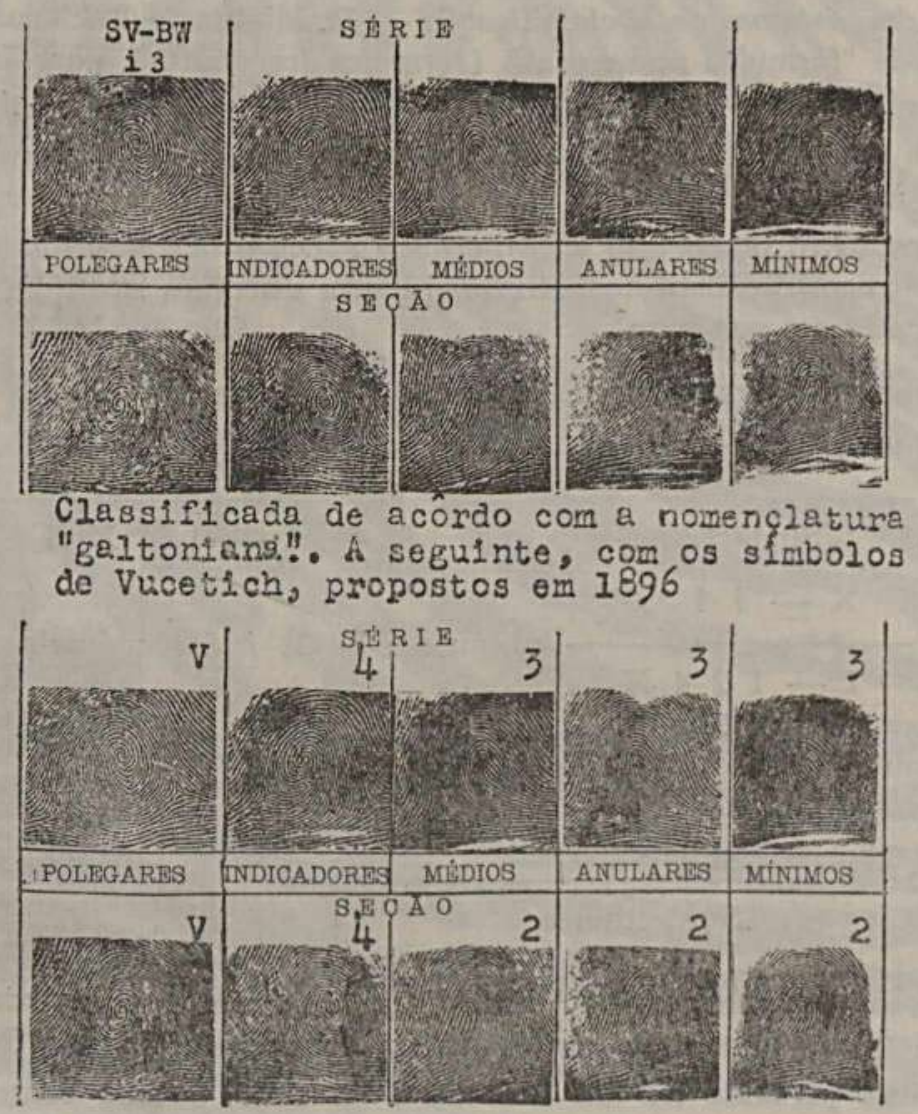

Fis. 53 - Classificação de individuais 


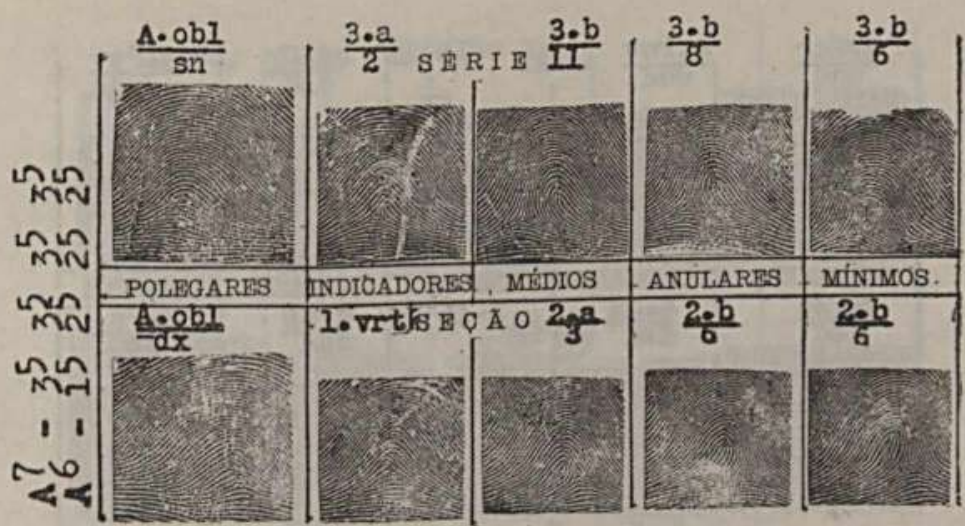

4 "fómula dact1loscópica" desta individuar no S1stema Vucotich, serla estruturada con forme se vê aq lado esquerdo

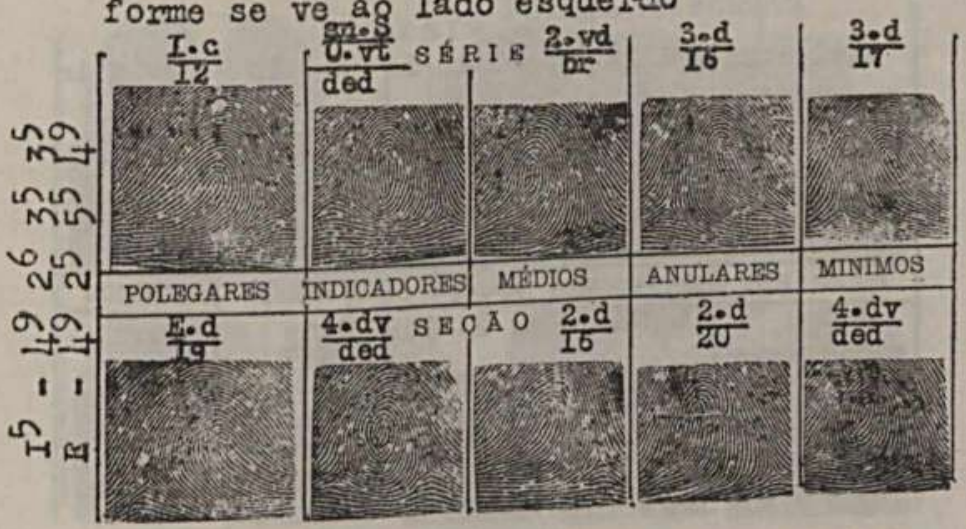

(Vide ledo esquerdo)

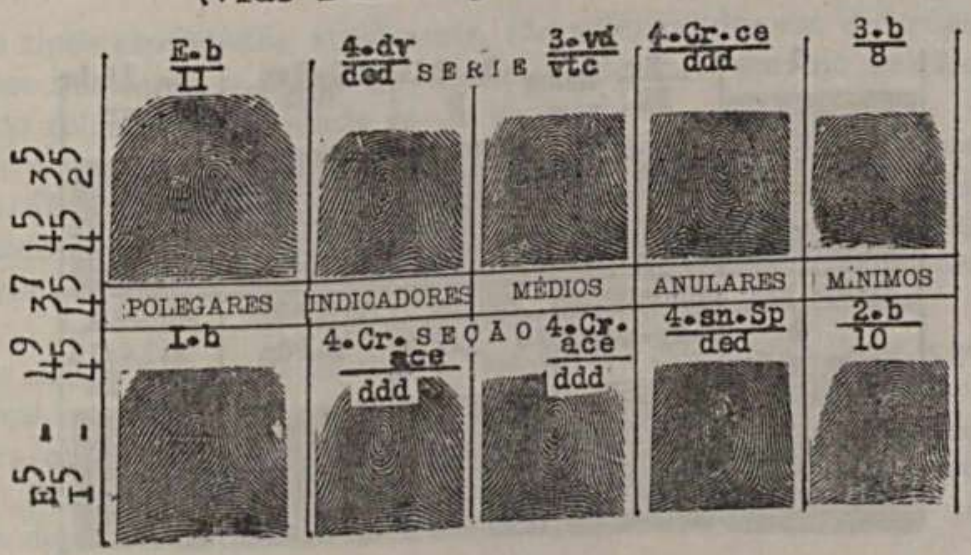

(Vide lado esquerdo)

Fig. 54 - Estas "individuais" estão subclasificadas de acôrdo com a Chave de Subtipos de Clóudio de Mendonça e classificadas segundo o Sistema Vucetich 

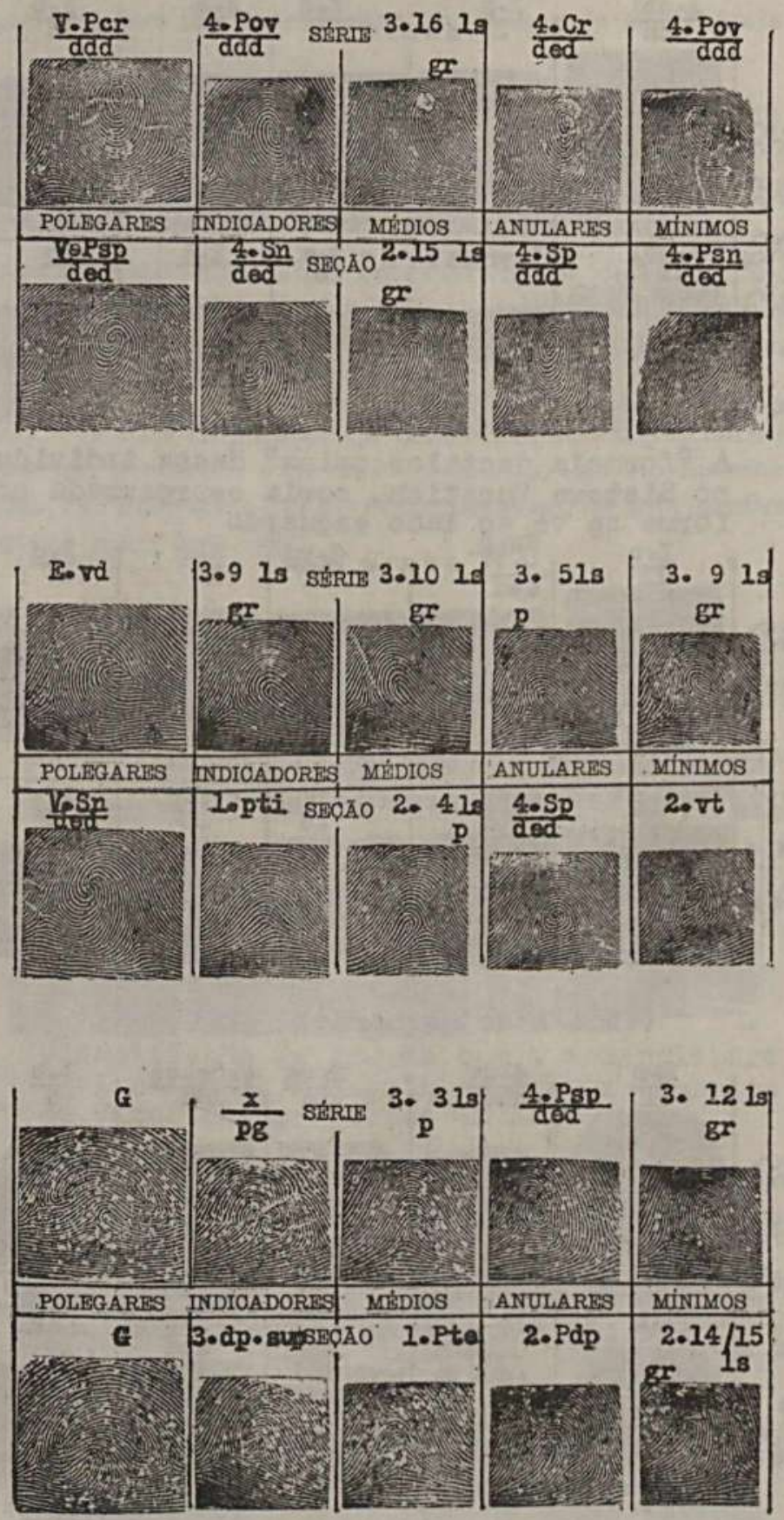

Fig. 55 - Classificadas de acôrdo com o Sistema Vucetich e subclassificadas, segundo o critério sugerido pela Comissão do Instituto Felix Pacheco 

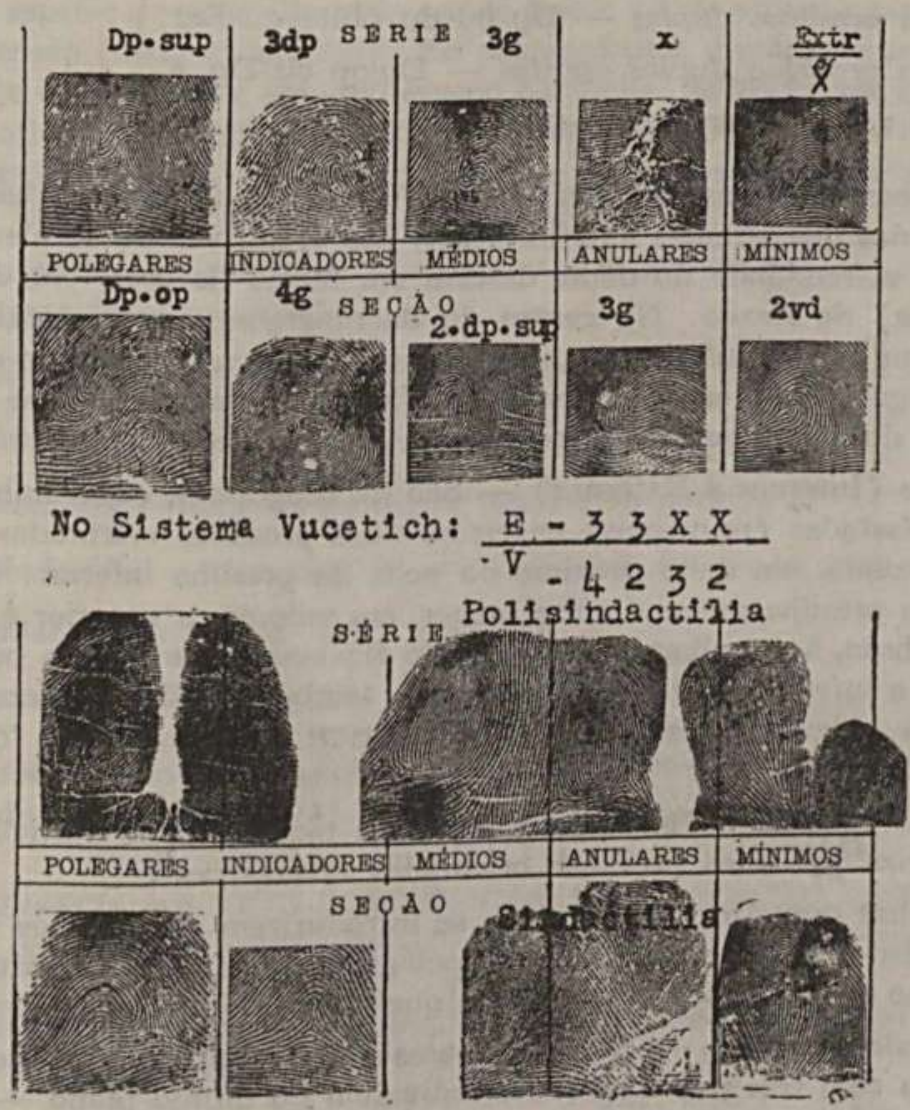

Fig. 56

Os tipos espiralados, atualmente, são subdivididos em dextrógiro, quando as linhas nucleares, a partir do centro, se desenvolvem no sentido dos ponteiros do relógio; sinistrógiros, se ao contrário.

Os circulares são subdivididos em centralizados e acentralizados. Este, quando não estiver dotado de um ponto central; aquêles, quando tal particularidade se achar presente. Estes subtipos foram, por VUCETICH, incluídos nos verticilos de núcleo normal (Espirais = concêntricos ou espirais) figura 51.

Os sinuosos, de acôrdo com a posição ou orientação do colchete inferior ou lateral, subclassificam-se de acôrdo com a "Chave" sugerida por VuCETiç ou outra que exigida seja em concurso; CLÁUdio DE MENDONÇA os subclassifica em dextroposto e sinistroposto; autores outros dáo outras denominações.

As demais especificações dêsse subtipos e dos demais serão mencionadas no "ponto" (item) 18.

Tipos especiais:

Nêstes tipos estão incluídos:

A presitha ganchosa - G ou g (Int. ou Ext.) 
As presilhas duplas - Dp ou dp (Int. ou Ext.)

As presilhas duplas opostas - Dp-op ou Dp, e

$\mathrm{O}$ verticilo ganchoso - $\mathrm{G}$.

Ganchosas (Internas e Externas) - As linhas nucleares se desenvolvem ao inverso das que citamos anteriormente, isto é, em vez de se elevarem em direção da extremidade do dedo, descem em forma de arco, em direção da prega (ruga) de flexão. No centro do dactilograma, aproximadamente, no ponto em que a linha inferior da presilha evolue para voltar ao lado de origem, um arco angular ou o esbôço de uma presilha ou de um verticilo se apresenta no interior do ângulo, dando origem a dactilograma complexos.

Duplas (Internas e Externas) - São dactilogramas, cujas linhas diretrizes mais afastadas (principais) encerram duas presilhas orientadas para um lado só e, ainda, um delta próximo do polo, da presilha inferior. Há, geralmente, uma presilha maior e outra menor, em volume; a superior é, de modo geral, ganchosa, à semelhança de um dedo flexionado, de grande ou pequena curvatura; a inferior, típica (normal). São, também, conhecidas como duplas superpostas. Algumas dessas espécies VUCETICH fez menção em "demais vasiedades" (Fig. 51).

Duplas opostas - Êste tipo, por muitos tomado como verticilo sinuoso, se caracteriza por duas presilhas orientadas inversamente.

As linhas diretrizes centrais, sem se introduzirem nos núcleos inflectidos, saem por lados distintos, consoante o polegar esquerdo da individual do primeiro plano da fig. 56 e os esquemas que serão mostrados nêste ponto".

Verticilo ganchoso - Desenhos raros e de aspecto complicado; ora, se apresentam com três presilhas (vide individual do último plano - polegares - da fig. 55, e indicador esquerdo da do primeiro plano de 56) no interior das diretrizes externas (fundamentais); ora, com elas e um arco angular ou com uma disposição de linhas caracterizando formas outras, imprevistas.

Tipos anômalos - Nessa categoria são inciuídos aquêles que, pela sua complexidade, não se enquadram nos tipos especificados ou descritos anteziormente.

Os desenhos dessa ordem e os defeituosos por cicatrizes Vucetich empregava, para representá-los na fórmula dactiloscópica, o $\mathrm{X}$.

Os técnicos do Rio empregam $X$ para os dedos amputados e os desenhos defeituosos ;com Xa (Xa) os chamados "anômalos" ou "teratológicos".

Anomalias - Essa, a classificação que se dá às mãos deformadas de nascimento.

As anomalias dividem-se em congênitas e em adquiridas. As primeiras. os indivíduos trazem ao nascer; as últimas são provenientes de acidentes, operaçōes, doenças.

A ancilose é uma anomalia; consiste na perda total ou parcial do movimento de um ou mais dedos e é produzida por tumores junto à articulação, seção dos tendōes em virtude de operação, incisão acidental ou repuxamento tos tecidos locais por cicatrizes. 
Essa espécie de anomalia pode ser de flexão (dedo voltado para a palma) ou de extensão (dedo distendido). No primeiro caso dispensa-se a tomada do competente dactilograma, em cujo espaço da "ficha" se anota um $X$ e, em síntese, o motivo pelo qual deixou de ser tomado o dactilograma ou, simplesmente, "ancilose", para justificar a ausência da impressão. No segundo, ao contrário, facilita a operação do dactiloscopador.

As anomalias exigidas no concurso para dactiloscopista do S.P.F. já foram esclarecidas no ponto 7 .

No Sistema Vucetich, são as seguintes:

Polidactilia - número de dedos superior ao normal

Ectrodactilia - número de dedos inferior ao normal

Megalodactilia - desenvolvimento exagerado de um ou mais dedos

Microdactilia - decios muito pequenos

Sindactilia - dedos ligados entre si.

O arquivamento e a pesquisa de individuais serão focalizados no "ponto" (item) 2 da prova prático-oral.

16. FREQÜÊNCIA DOS TIPOS FUNDAMENTAIS E SUBTIPOS NOS DESENHOS DIGITAIS, SEGUNDO O MÉTODO VUCETICH - DESENHOS DE TRANSIÇÃO

Fréqüência dos tipos - Em todos os arquivos dactiloscópicos considerase a seguinte percentagem:

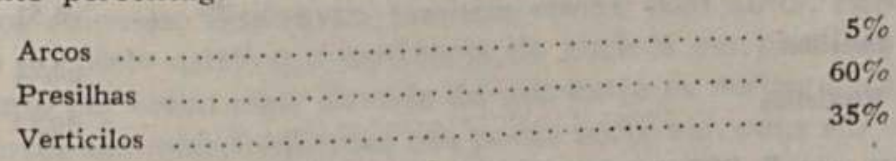

Por dedo - Em 100.000 dactilogramas (10.000) individuais OLORIZ encontrou a percentagem seguinte:

\begin{tabular}{|c|c|c|c|c|}
\hline \multirow{2}{*}{ MÃO DIREITA } & \multirow{2}{*}{$\mathrm{ARCOS}$} & \multicolumn{2}{|c|}{ PRESILALAS } & \\
\hline & & I & E & \\
\hline \multirow[t]{2}{*}{ 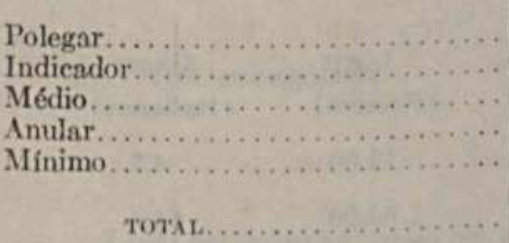 } & $\begin{array}{r}3,55 \\
24,57 \\
13,52 \\
3,58 \\
2,18\end{array}$ & $\begin{array}{l}0,09 \\
6,00 \\
0,44 \\
0,22 \\
0,04\end{array}$ & $\begin{array}{r}16,09 \\
9,90 \\
23,81 \\
16,21 \\
27,43\end{array}$ & $\begin{array}{r}16,37 \\
11,39 \\
6,26 \\
16,11 \\
5,58\end{array}$ \\
\hline & 47,40 & 6,79 & 93,44 & 55,71 \\
\hline
\end{tabular}


Revista do Serviço Público - Fevereiro - 1955

\begin{tabular}{|c|c|c|c|c|}
\hline \multirow{2}{*}{ MÃO ESQUERDA } & \multirow{2}{*}{$\operatorname{ARCOS}$} & \multicolumn{2}{|c|}{ PRESILHAS } & \multirow{2}{*}{ VERTICILOS } \\
\hline & & I & E & \\
\hline 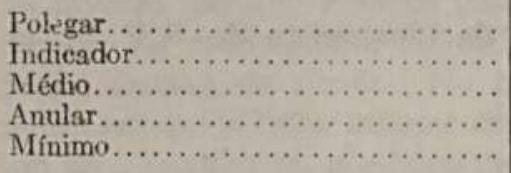 & $\begin{array}{r}7,25 \\
23,14 \\
15.59 \\
4,07 \\
2,55\end{array}$ & $\begin{array}{l}17,02 \\
11,06 \\
21,09 \\
18,55 \\
25,52\end{array}$ & $\begin{array}{l}0,13 \\
5,50 \\
0,50 \\
0,38 \\
0,05\end{array}$ & $\begin{array}{r}15,52 \\
10,46 \\
5,86 \\
11,25 \\
4,20\end{array}$ \\
\hline тотАL.... & 52,60 & 93,21 & 6,56 & 44,29 \\
\hline
\end{tabular}

De acôrdo com os quadros acima, em 100,000 dactilogramas, tem-se a seguinte ocorrência de tipos:

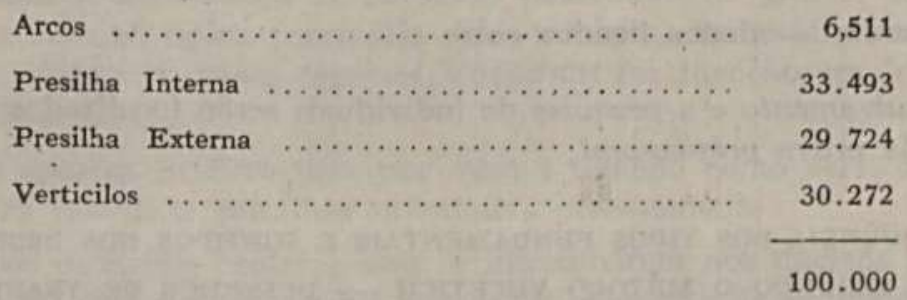

Percentagem - Êsses 100.000 tipos, estudados isoladamente, oferecem:

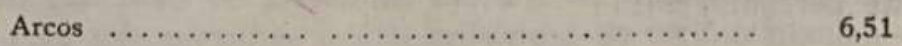

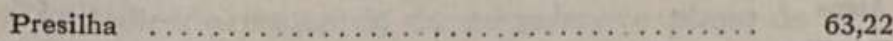

Verticilos ......................... 30,27

GaLton, em 5.000 pessoas, encontrou:

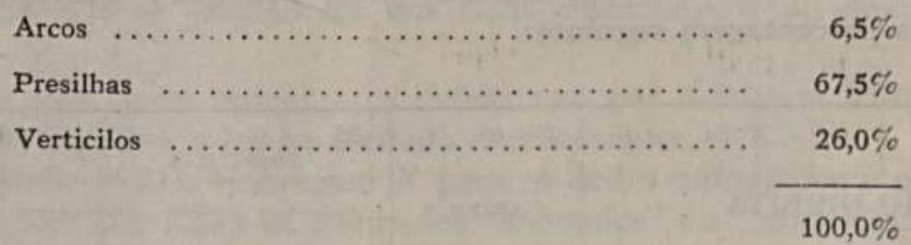

Outros autores:

\begin{tabular}{|c|c|c|c|}
\hline & $\begin{array}{c}\text { BONNEVIE } \\
\text { (Noruegueses) }\end{array}$ & $\begin{array}{r}\text { LoTH } \\
\text { (Polacos) }\end{array}$ & $\begin{array}{c}\text { GASTI } \\
\text { (Italianos) }\end{array}$ \\
\hline Arcos & 7,4 & 12,00 & 4,7 \\
\hline Presilhas $\ldots . . .$. & 66,9 & 63,00 & 58,4 \\
\hline Verticilos $\ldots \ldots \ldots$... & $-25,6$ & 24,00 & 36,4 \\
\hline
\end{tabular}




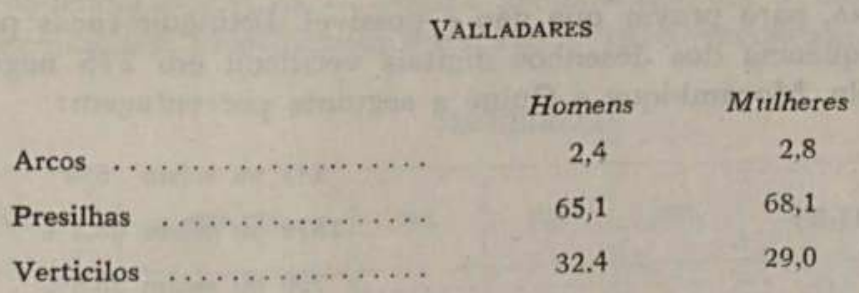

XAVIER DA SILVA

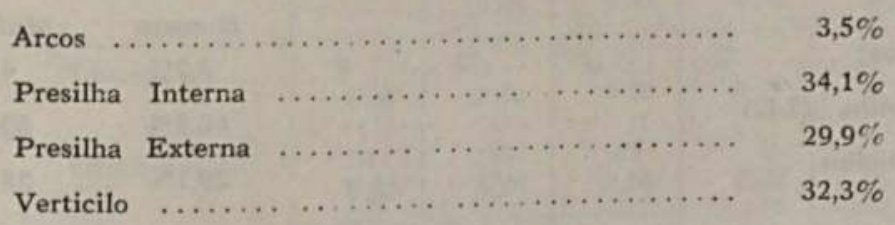

A porcentagem, admitida universalmente, é a que ficou esclarecida no início dêste "ponto", isto é:

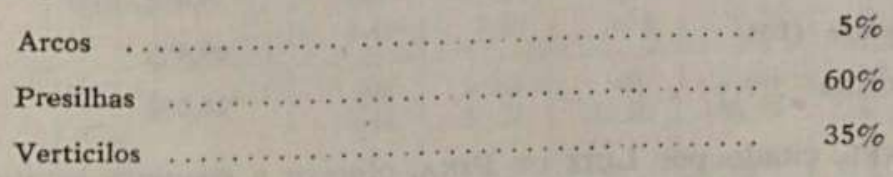

Segundo certos autores, as presilhas são mais frequientes na raça branca.

DUfauX, citado por MANUEL ViotTr, informou que o verticilo é muitc comum nos chineses; BONNEVIE, também citada pelo autor, citado, observou nos povos do oeste asiático a existência de núcleos em presilhas e verticilos, em um tanto por cento mais elevada do que entre os noruegueses e britânicos e que os arcos são mais frequientes nos povos norte europeus em contraposição aos do oeste asiático.

Inúmeros autores se dedicaram ao estudo dos desenhos falangéticos sob o ponto de vista racial.

BonNevie, já citada, informou, em 1923, que os arcos, presilhas e verticilos variavam de povo para povo, conforme o que abaixo se reproduz:

Nos japoneses

\begin{tabular}{|c|c|}
\hline $\operatorname{Arcos} \ldots \ldots \ldots \ldots$ & $1.2 \%$ \\
\hline Verticilos . & $45,0 \%$ \\
\hline Arcos . & $7 \%$ \\
\hline Verticilos . & \\
\hline
\end{tabular}

LOCARD admite que as raças menos evoluídas ou progressivas apresentam maior percentagem de verticilos. 
LUIZ DE PINA, para provar que não é possível distinguir raças pela frequiência ou infreqüência dos desenhos digitais verificou em 275 negros das colonias de Angola, Moçambique e Guiné a seguinte porcentagem:

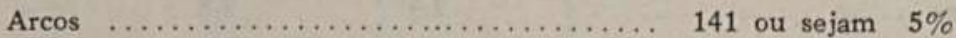

Presilhas (I-E) $\ldots \ldots \ldots \ldots \ldots \ldots \ldots \ldots \ldots \ldots \ldots$ ou sejam $68,3 \%$

Verticilos $\ldots \ldots \ldots \ldots \ldots \ldots \ldots \ldots \ldots \ldots \ldots \ldots \ldots \ldots$ ou sejam $26,5 \%$

Carlos Lopes, Valadares e Luiz de Pina encontraram a porcentagem seguinte, em portugueses brancos, de ambos os sexos:

\begin{tabular}{|c|c|c|}
\hline & Homens & Mulheres \\
\hline Arcos & $3,7 \%$ & $4,8 \%$ \\
\hline Presilha (I-E) & $66,9 \%$ & $69,4 \%$ \\
\hline Verticilos . & $29,1 \%$ & $25,6 \%$ \\
\hline
\end{tabular}

Nos negros africanos:

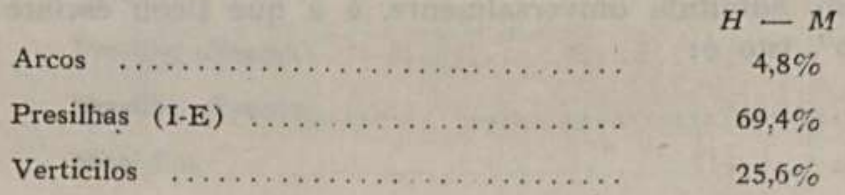

HENCKEL, citado por LUIZ DE PINA, oferece a seguinte estatística:

\begin{tabular}{|c|c|c|c|}
\hline POR'TUGUESES & $\operatorname{ARCOS}$ & PRESILH IS & VERTICILOS \\
\hline 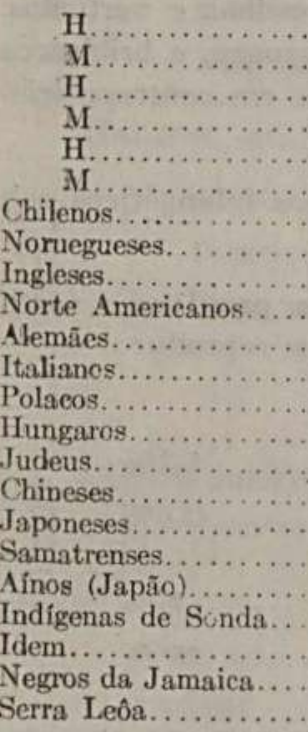 & $\begin{array}{r}6,1 \% \\
6,7 \% \\
20,4 \% \\
2,8 \% \\
4,2 \% \\
5,9 \% \\
4,8 \% \\
7,4 \% \\
4,8 \% \\
5,2 \% \\
7,4 \% \\
4,7 \% \\
12,0 \% \\
5,0 \% \\
4,2 \% \\
1.4 \% \\
2.6 \% \\
1.7 \% \\
2,9 \% \\
2,3 \% \\
1,9 \% \\
10,8 \% \\
3,6 \%\end{array}$ & $\begin{array}{l}66,9 \% \\
66,0 \% \\
65,1 \% \\
68,1 \% \\
68,6 \% \\
72,4 \% \\
58,0 \% \\
66,9 \% \\
71,4 \% \\
62,7 \% \\
63,0 \% \\
58,4 \% \\
63,0 \% \\
62,7 \% \\
53,0 \% \\
47,6 \% \\
51,8 \% \\
61,9 \% \\
65,2 \% \\
62,8 \% \\
62,8 \% \\
59,3 \% \\
57,3 \%\end{array}$ & $\begin{array}{l}26,9 \% \text { C. Lopes } \\
27,2 \% \text { Valladares } \\
32,4 \% \text { Vall } \\
29,0 \% \\
26,9 \% \text { Pina } \\
21,5 \% \\
26,3 \% \text { Henckel } \\
25,6 \% \text { Bonnevie } \\
25,3 \% \text { Kutsuna } \\
32,1 \% \text { Cummins e Midlo } \\
29,2 \% \text { Gasti } \\
36,4 \% \text { Gasti } \\
24,0 \% \text { Loth } \\
32,3 \% \text { Bonnevie } \\
42,7 \% \text { Cummins } \\
50,6 \% \text { Kubo } \\
45,1 \% \text { Furuse } \\
45,1 \% \text { K.Zwann } \\
65,2 \% \text { Hasebe } \\
34,7 \% \text { Zwann } \\
46,2 \% \text { Kanaseki } \\
29,9 \% \text { Daven Port e Steg. } \\
39,9 \% \text { Cummins }\end{array}$ \\
\hline
\end{tabular}


Freqüência dos tipos - ARgeU GuIMARÃEs, em 5.000 depositantes da Caixa Econômica, identificados em 1915 e 1916, encontrou:

MÃO DIREITA

\begin{tabular}{|c|c|c|c|c|c|c|c|}
\hline TIPOS & SUBTIPOS & POL. & IND. & MED. & AN. & srr. & RESOMO \\
\hline Areos & $\begin{array}{l}\text { Simples..... } \\
\text { Angulares,... }\end{array}$ & $\begin{array}{l}135 \\
2.70 \\
- \\
-\end{array}$ & $\begin{array}{c}515 \\
10,30 \\
137 \\
2,74\end{array}$ & $\begin{array}{l}397 \\
5.94 \\
34 \\
0,68\end{array}$ & $\begin{array}{c}93 \\
1.86 \\
6 \\
0,12\end{array}$ & $\begin{array}{c}60 \\
1.20 \\
6 \\
0,72\end{array}$ & $\begin{array}{r}1.279 \\
5,11\end{array}$ \\
\hline Presilha Interna & $\begin{array}{l}\text { Típicas ...... } \\
\text { Verticiladas. }\end{array}$ & $\begin{array}{l}9 \\
0,18 \\
16 \\
0,32\end{array}$ & $\begin{array}{l}675 \\
13,50 \\
195 \\
3,90\end{array}$ & $\begin{array}{l}41 \\
0,82 \\
25 \\
0,50\end{array}$ & $\begin{array}{r}27 \\
0,54 \\
15 \\
0,30\end{array}$ & $\begin{array}{r}5 \\
0,10 \\
7 \\
0,14\end{array}$ & $\begin{array}{c}1.015 \\
4.06 \%\end{array}$ \\
\hline Presilha Fxterna & $\begin{array}{l}\text { Tipicas........ } \\
\text { Verticiladas.... }\end{array}$ & $\begin{array}{l}2.280 \\
45,60 \\
206 \\
4,12\end{array}$ & $\begin{array}{c}1.642 \\
32,84 \\
140 \\
2,80\end{array}$ & $\begin{array}{l}3.537 \\
70,74 \\
137 \\
2,74\end{array}$ & $\begin{array}{c}2.076 \\
41,52 \\
528 \\
10,56\end{array}$ & $\begin{array}{c}3.544 \\
70,88 \\
524 \\
10,48\end{array}$ & $\begin{array}{l}14.614 \\
58,45 \%\end{array}$ \\
\hline Verticilos. & $\begin{array}{l}\text { Espirais....... } \\
\text { Sinuosos....... } \\
\text { Ovoidais....... } \\
\text { Ganchosos..... }\end{array}$ & $\begin{array}{c}1.032 \\
20.64 \\
632 \\
12.64 \\
484 \\
9,68 \\
186 \\
3,72\end{array}$ & $\begin{array}{l}1.062 \\
21.24 \\
136 \\
2.72 \\
262 \\
5,24 \\
192 \\
3,84\end{array}$ & $\begin{array}{l}560 \\
11.20 \\
43 \\
0,86 \\
202 \\
4,04 \\
97 \\
1,94\end{array}$ & $\begin{array}{l}1.691 \\
33.82 \\
25 \\
0,50 \\
393 \\
7,86 \\
113 \\
2,26\end{array}$ & $\begin{array}{l}594 \\
11,38 \\
13 \\
0,26 \\
183 \\
3,66 \\
\\
34 \\
0,68\end{array}$ & $\begin{array}{l}7.934 \\
31.73 \%\end{array}$ \\
\hline Inclassificáveis... & & $\begin{array}{l}2 \\
0,04 \\
18 \\
0,36\end{array}$ & $\begin{array}{l}{ }^{9} \\
0,18 \\
35 \\
0,70\end{array}$ & $\begin{array}{l}4 \\
0,08 \\
23 \\
0,46\end{array}$ & $\begin{array}{l}6 \\
0,12 \\
27 \\
0,54\end{array}$ & $\begin{array}{l}5 \\
0,10 \\
29 \\
0,58\end{array}$ & \\
\hline
\end{tabular}

Nota: Presilhas trticiladas - Neste grupo o autor incluiu as incadidas, ganchosas e duplas.

RoBerto Thut, Perito dactiloscópico do Serviço de Identificação de São Paulo, em Ocorrência dos Desenhos Papilares na Impressão Digital (Separata dos "Arquivos de Polícia e Identificação" - vol. II - 1938-39, n. ${ }^{\circ} 1$ ), São Paulo, mencionou a seguinte distribuiçăo dos tipos fundamentais em 3.130 fichas, arquivadas até 31 de dezembro de 1936, no Arquivo Monodactilar baseado na classificaçăo decimal.

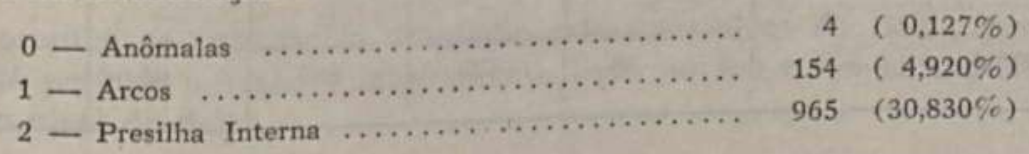




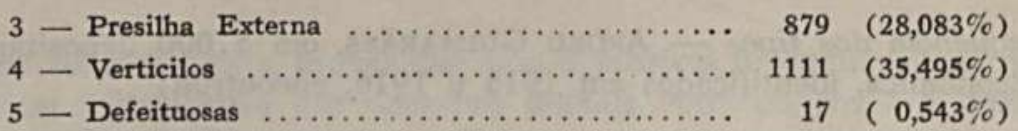

Os Arcos, assim se subdividem:

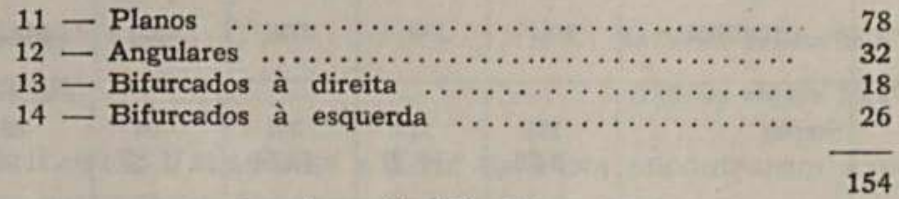

\section{2 - Presilha Interna}

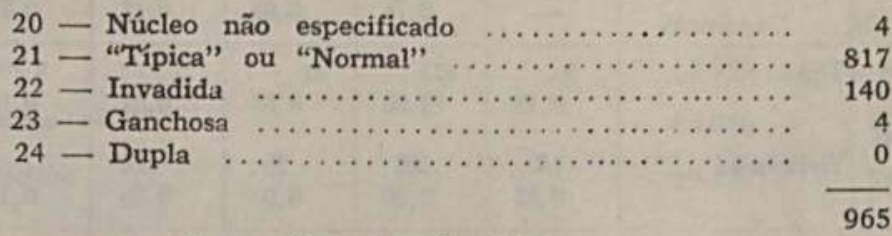

3 - Presilha Externa

30 - Núcleo não especificado $\ldots \ldots \ldots \ldots \ldots \ldots \ldots \ldots$

31 - "Típica" ou "Normal" ................. 740

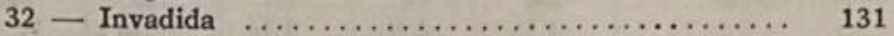

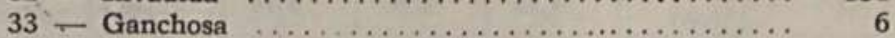

$34 \ldots$ Dupla ........................... 2

\section{4 - Verticilos}

879

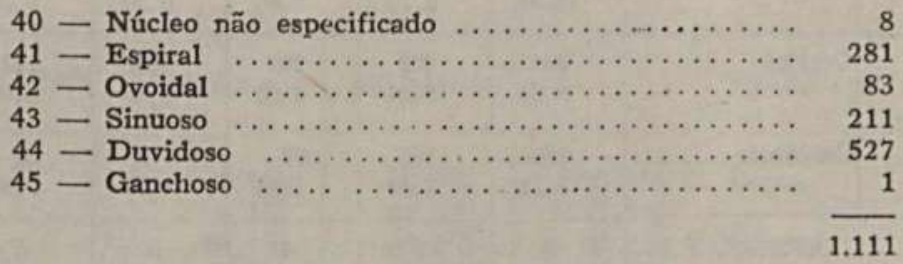

THuT verificou, também, a percentagem das presilhas pela subclassificação do núcleo (contagem de linhas). Os verticilos, pela subclassificação nuclear com a disposição dos deltas, oferecem a seguinte distribuição:

\begin{tabular}{|c|c|c|c|c|c|}
\hline VERTICILOS & $\begin{array}{l}\text { DELTA NÃO } \\
\text { ESPECIF. }\end{array}$ & DDD & DED & c o & TOTAL \\
\hline 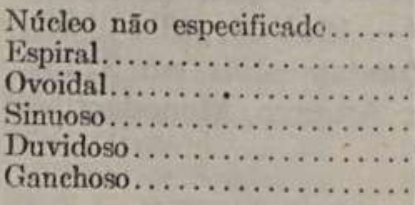 & $\begin{array}{r}0 \\
3 \\
0 \\
1 \\
4 \\
-\end{array}$ & $\begin{array}{r}0 \\
100 \\
34 \\
79 \\
220 \\
-\end{array}$ & $\begin{array}{r}8 \\
151 \\
34 \\
125 \\
270 \\
-\end{array}$ & $\begin{array}{r}0 \\
27 \\
15 \\
6 \\
33 \\
-\end{array}$ & $\begin{array}{r}8 \\
281 \\
83 \\
211 \\
527 \\
1\end{array}$ \\
\hline TOTAL... & 8 & 433 & 588 & 81 & 1.111 \\
\hline
\end{tabular}




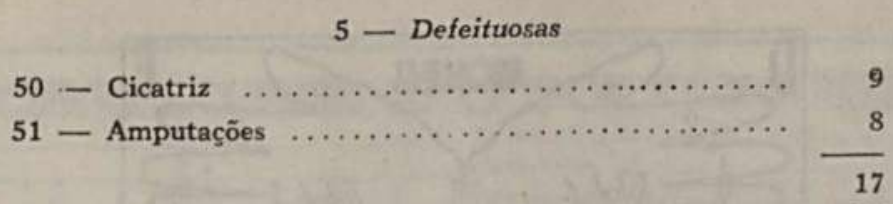

Os esquemas que seguem, mostram a distribuição dos tipos fundamentais pelos dez dedos, cálculos sôbre 3.130 fichas, por R. THur.

Desenhos de transição -. Essa, a denominação que se dá aos dactilogramas que apresentam duplas formas à classsificação primária.

Os técnicos do Instituto Felix Pacheco definem os tipos transicionais na "Nova subclassificação do Método de Vucetich", publicada no Rio de Janeiro, em 1952, conforme se verá no desenvolver dêste ponto.

\section{Diferenciaçäo entre o arco simples e o angular}

“..... para que um arco seja considerado angular, é necessário e suficiente que apresente pelo menos uma linha acentuadamente angular e inteiramente livre em sua angulosidade. Considerar-se-á simples, portanto, o arco em que, mesmo se encontrando essa angulosidade, apresente-se ela prjudicada por uma linha curva que a ela se ligue.

Não confundir o arco tendiforme (angular), cujo chamado páu-de-tenda é envolvido por uma linha muitas vêzes curva (sem apresentar, portanto, uma acentuada angulosidade) e que atravesse o desenho de lado a lado, podendo ou não estar ligada ao páu-de-tenda (c-d).

\section{Diferenciação entre o arco simples perturbado e o arco apresilhado}

$\mathrm{O}$ arco simples perturbado, quando caracterizado por uma bifurcação ou divergência de linhas, na forma exposta na definição (e-e), pode tender à formação de uma laçada, confundindo-se, em seu aspecto, com um arco apresilhado. Nêsse caso, só será considerado apresilhado quando se caracterizar a laçada por uma perfeita inflexão ( $\left.e^{\prime \prime}-\mathrm{e} "\right)$.

\section{Diferenciação entre $o$ arco angular e o apresilhado}

“...... apresilhado é o arco que apresenta delta e laçada não independentes. Para que tal se considere é preciso, portanto, que a laçada se caracterize tanto quanto na presilha, por uma perfeita inflexão, só não se conformando em presilha por uma ligação com o delta ( $\mathrm{f}-\mathrm{g}$ ) ou com outra linha que o circunscreva $(\mathrm{h}-\mathrm{i})$.

\section{Diferenciação entre o arco e a presilha}

A presilha se caracteriza, fundamentalmente, além do delta, por uma laçada de perfeita inflexăo e inteiramente livre no seu ramo ascendente e a partir do nível do delta. 

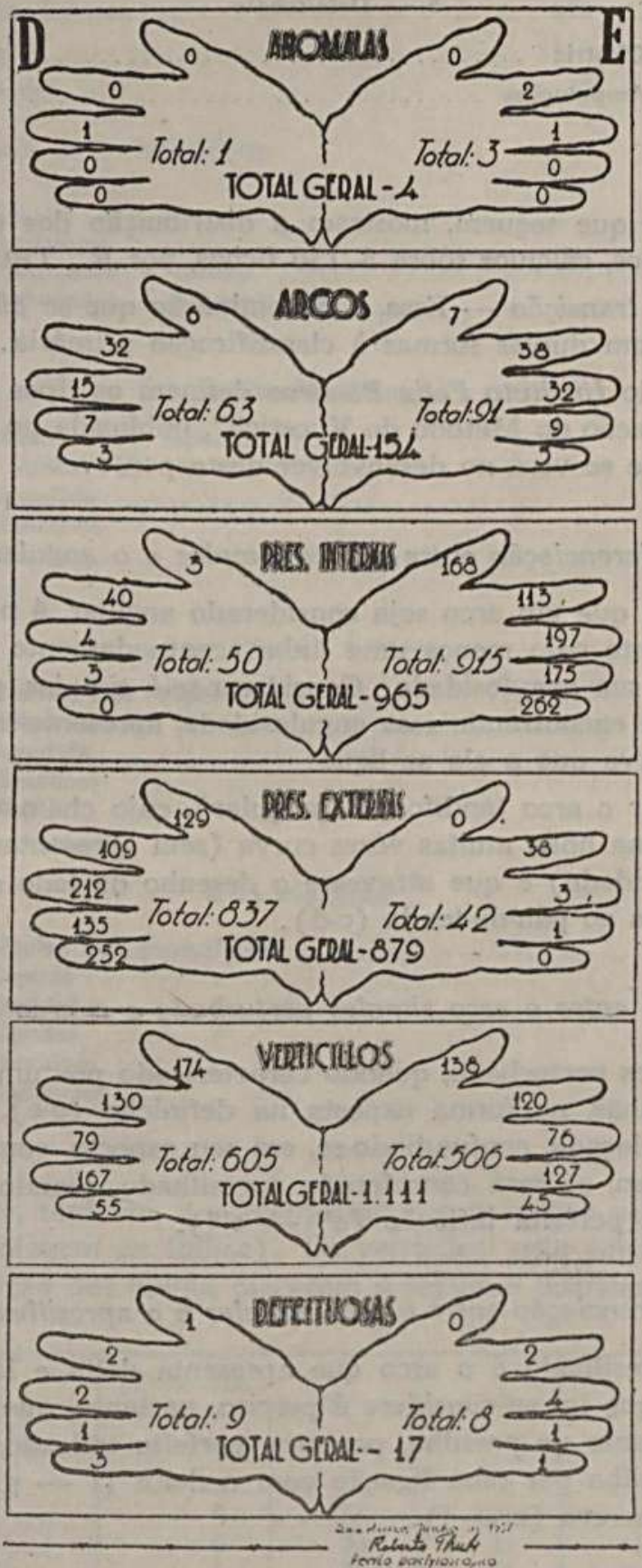

Fig. 57 - Esquemas reproduzidos de Ocorrência dos desenhos papilares na impressão digital, local citado 


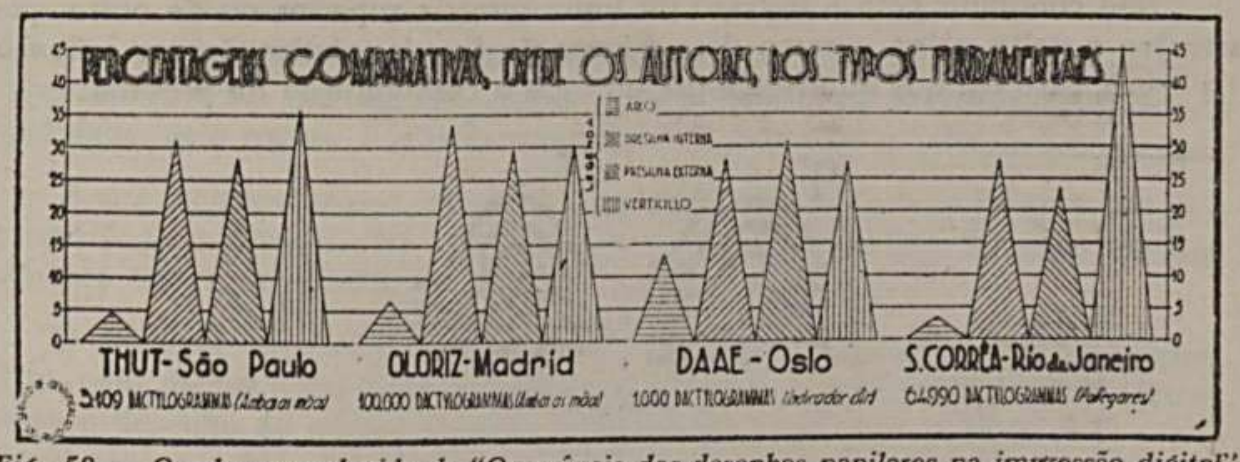

Fiǵ. 58 - Quadro reproduzido de "Ocorréncia dos desenhos papilares na imjressão digital"

("Arquivos de Polícia e Identificação" - Separata - Sảo Patulo, 1938-39, n. 1)

Quando a laçada se formar da linha diretriz superior, ou no seu ramo ascendente a ela estiver ligada bem como a uma linha que circunscreva o delta $(\mathrm{m}-\mathrm{n}-\mathrm{o}-\mathrm{p})$ teremos o arco apresilhado.
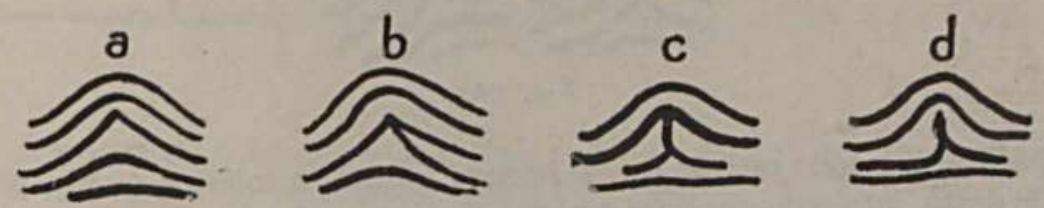

Fig. 59
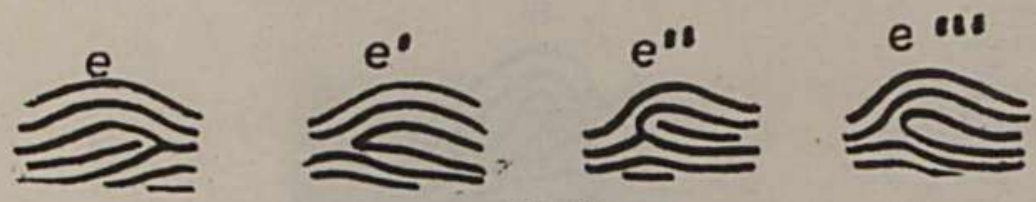

Fig. 60
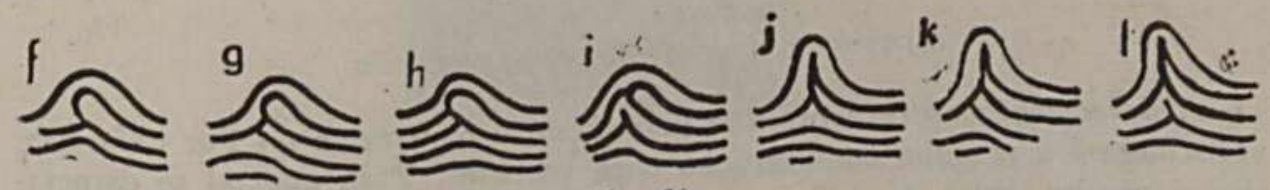

Fig. 61
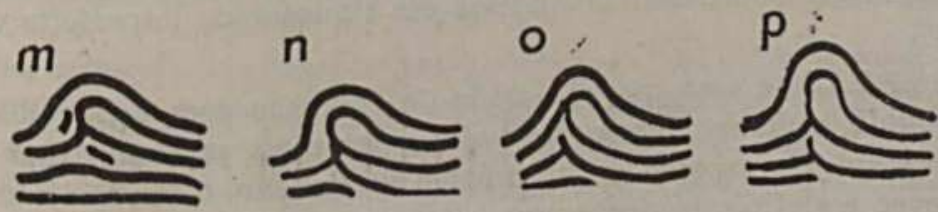

Fig. 62 
Não confundir com a invasão da linha diretriz superior ou de outra que envolva o delta, sôbre o ramo descendente da laçada, abaixo de sua inflexão $(q-r)$, caso em que não ficará prejudicada a configuração da presilha.

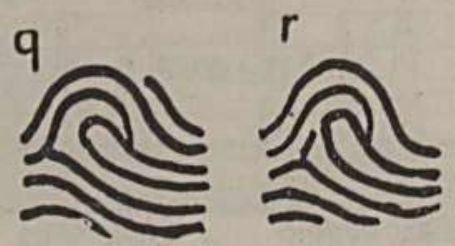

Fig. FC

Será considerado arco, o desenho digital que apenàs esboçar uma laçada que, embora livre, não se caracterize por uma perfeita inflexão, formando, antes, um ângulo $(s-t)$.

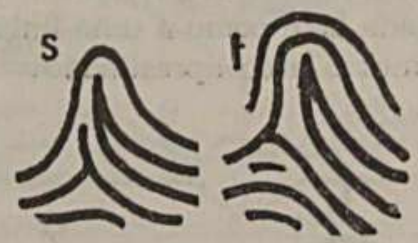

Fig. 64

Quando a laçada estiver ligada apenas à diretriz inferior (u) e, portanto, a partir desta, inteiramente livre em seu ramo ascendente, estará caracterizada a presilha.

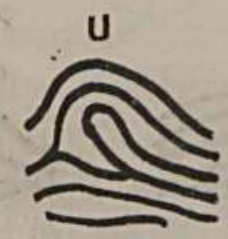

Fig, 65

Transição de presilha para verticilo

Diferenciação entre a presilha verticilada e o verticilo - Por definição, verticilada é a presilha em transição para verticilo. Para que tal se caracterize, é preciso, antes de mais nada, que tenha conformação de verticilo, isto é, que apresente um faiso núcleo verticilado, formado por linhas convergentes entre si (angulares) ou desenvolvendo-se em sir:uosidade imperfeita ou espiral incipiente.

Se não há, nêste caso, possibilidade de confusão com a presilha simplesmente invadida, cuja incidência de linhas, por mais profunda que seja, não chega a apresentar o aspecto de um núcleo verticilado, o mesmo não se dá ao se estabelecer e definir as fronteiras que separam a presilha verticilada do 
verticilo pròpriamente dito. Nesta diferenciação, é indispensável o estabelecimento de regras tão rígidas quanto possível e capazes de abranger, se não a totalidade, pelo menos a grande maioria dos casos que se possam apresentar.

Assim, considerar-se-á verticilo todo desenho que, em seu núcleo simples espiral (a) ou circular (b) apresentar pelo menos duas linhas curvas e externamente livres, separando o delta do centro do núcleo.

O desenho de núcleo sinuoso será considerado verticilo desde que apresente, pelo menos, uma linha sinuosa perfeitamente caracterizada (c). Excetua-se o desenho de núcleo sinuoso, formado de duas alças simples $(\mathrm{d}-\mathrm{e})$. o qual será considerado presilha verticilada.

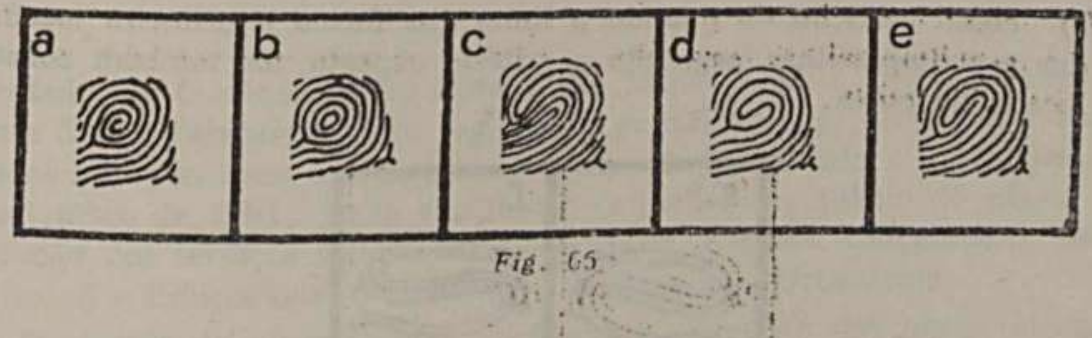

Nos desenhos de núcleo complexo, formado de linhas angulares, qualquer que seja a sua forma de desenvolvimento (espiralada, ovoidal, etc.) bastará uma linha curva e externamente livre, envolvendo o núcleo ou parte dêle, em sua face voltada para o delta, para que, se caracterize o verticilo.

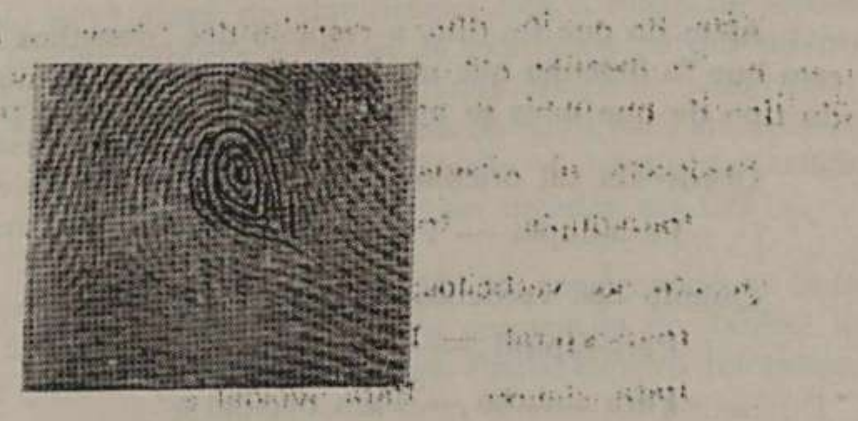

Fig. 67

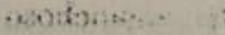

\section{Diferenciação entre as duplas opostas e os verticilos sintosas}

As duplas opostas, desenhos formados de duas presilhas independentes e opostas entre si, constituem, por isto mesmo, desenhos de dois deltas, um de cada lado da polpa digital, de aspecto muitas vezes semelhante ao verticilo sinuoso, que pode também apresentar a configuração de duas presilhas: opos. tas, só não se caracterizando como dupla, pela independência dessàs pseudospresilhas. 
Êsses tipos de transição serão clasificados:

a) como dupla - quando a linha da primeira laçada da presilha superior, seguindo-se a partir da altura do respectivo delta, fôr passar sôbre o delt a oposto ou com êle coincidir;

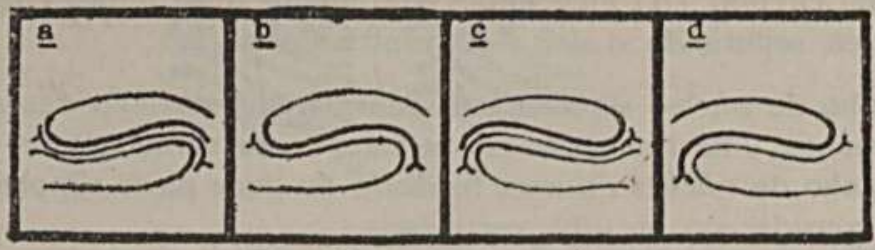

Fig. 68 - Duplas opostas

b) como verticilo - quando a linha que forma a primeira laçada de uma das pseudo-presilhas, seguindo o critério exposto, fôr também constituir uma laçada da outra.

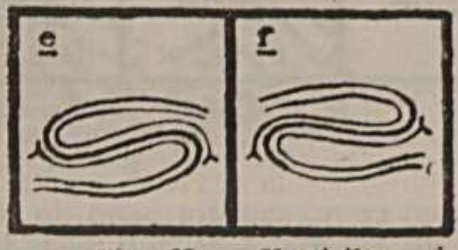

Fig. $69-$ Verticilos

\section{Transição entre os diversos subtipos}

Além do que foi dito, a respeito dos "desenhos de transição", estabeleceram que "o desenho que não se definir quanto ao núcleo, terá a denominação do tipo de que mais se aproximar, com o prefixo PARA".

Obedecida tal orientação, tem-se:

Para-dupla - Para-ganchosa

Quanto aos verticilos:

$$
\begin{gathered}
\text { Para-espiral - Para circular } \\
\text { Para sinuoso - Para ovoidal e } \\
\text { Para-ganchoso - ganchoso }
\end{gathered}
$$

A Operação Município - tal como a interpretou o eminente Senador - é uma concepção arrojada e dinâmica, em cujo bojo o Plano Nacional de Obras e Serviços Municipais torna perfeitamente exequível a progressiva solução dos principais problemas dos Municípios brasileiros. Projeto elaborado com larga visão de estadista e extraordinário rigor técnico, levando em consideração, ao mesmo tempo, os imperativos da Constituição da República e os princípios, direitos e reivindicaçōes da Carta dos Municípios. A Operação Municipio é, na verdade, a maior conquista das Prefeituras e Câmaras Municipais do Brasil - ponto culminante e a mais alta expressão técnico-cultural do movimento municipalista. 